\title{
Multi-Class Community Structure within a Temperate Freshwater Wetland Complex: Evidence for the Metacommunity
}

\author{
James E. McKenna, $\mathrm{Jr}^{*}$
}

Tunison Laboratory of Aquatic Science, USGS/Great Lakes Science Center, Cortland, NY 13045, USA

\begin{abstract}
Wetlands are ecologically valuable and complex systems that both link and buffer aquatic and terrestrial systems. Spatial aspects and metacommunity concepts help explain community structure and dynamics, but metacommunity dynamics have not been applied to multiple interacting classes of organisms in temperate wetlands. The aim of this study was to 1) quantify significant patterns of wetland community structure within a large wetland in Central New York, USA at a variety of scales and on several trophic levels in relation to key elements of the physical and biological environment, and 2) evaluate four paradigms of metacommunity dynamics that may explain that community structure. Data on assemblages of three major interacting community components, having different dispersal abilities (birds, fish, and invertebrates), and environmental conditions were collected from aquatic habitats of different size and connectivity. Analysis of diversity and composition in relation to a size-connectivity index (SCI) showed clear evidence of spatial or environmental influences, or both for all major taxa. Aquatic organisms formed distinct assemblages whose spatial arrangement and associated environmental conditions were consistent with one of the two spatially explicit metacommunity paradigms, Mass Effect, Species Sorting, or both. The study wetland was a relatively productive, metacommunity, populated by members of a post-glacial species pool, and maintained within three major habitat types, large pools connected to small ditch-like habitats, and isolated pools. Metacommunity dynamics differed by organism class, but habitat was clearly heterogeneous, eliminating Patch Dynamics and Neutral Models. Aerial insects showed little metacommunity dynamics, with a weak habitat condition link to the Species Sorting mechanism. Aquatic invertebrates and aquatic vertebrates showed evidence of both Mass Effect and Species Sorting, with strong environment influences emphasizing the latter; social behavior modified Species Sorting for aquatic birds. The multi-taxon approach revealed important couplings among wetland community components; active management of wetland habitat via altered water supply and connectivity may allow aquatic organisms to escape disturbance and recolonize habitat, but will likely change community structure. Controlled experiments on organism demographics and movements would help clarify the processes of community maintenance in this and other wetlands.
\end{abstract}

Keywords: Wetlands Metacommunity, Community Dynamics, Aquatic Invertebrates, Freshwater Fish, Marsh Birds, Multiclass assemblages, Biodiversity.

\section{INTRODUCTION}

Wetlands are essential components of healthy terrestrial and aquatic ecosystems and serve to both link and buffer those systems. They perform a variety of ecological services and provide habitat for fish and other wildlife (Committee on Restoration of Aquatic Ecosystems 1992). However, vast areas of wetlands have been drained and otherwise altered throughout the United States (Steedman and Regier 1987, Dahl 1990, Jude and Pappas 1992). Roughly 50\% of the original Great Lakes Basin wetlands have been eliminated (US Fish and Wildlife Service 1988) and 60\% of New York's wetlands have been lost to various types of development (Committee on Restoration of Aquatic Ecosystems 1992). The Montezuma Wetlands Complex (MWC) (including the Montezuma National Wildlife Refuge $[\mathrm{MNWR}])$ is one of the few remaining, extensive wetland

*Address correspondence to this author at the Tunison Laboratory of Aquatic Science, USGS/Great Lakes Science Center, Cortland, NY 13045, USA; Tel: 607-753-9391; Fax: 607-753-0259; E-mail: jemckenna@usgs.gov areas, in New York State. Several classes of aquatic organisms are integral to the structure and function of the Montezuma wetland. Birds and fish are of prime interest to wetland managers, and both are dependent on invertebrates (either directly or indirectly). However, basic biotic community structure and function are poorly known in many wetlands and the importance of multiple classes of aquatic organisms (and their interactions) has rarely been measured in wetlands (Mitsch and Gosselink 2006). For example, abundance of birds and some aquatic insects (especially, biting insects) in wetlands can be obvious and a diverse assemblage of fish is known to use wetlands, but it is difficult to generalize about the role of freshwater marshes in supporting fish (Mitsch and Gosselink 2006). Similarly, much remains unknown about wetland aquatic invertebrates, although their importance as links between primary production and consumers, including fish and waterfowl, is clear (Voigts 1976; Weller 1981; Krieger 1992; Brooks 2000; Zimmer et al. 2000). Consumption and emigration of invertebrates can represent a substantial export of wetland production (Brinson et al. 1981). Birds are highly mobile predators that feed on both fish and invertebrates, but the 
intensity of bird effects on a wetland are pulsed due to semiannual migrations. Many large wetlands are necessary to accommodate these global-scale migration events and local wetland populations (e.g., fish) respond to this influence (Baldassarre and Bolen 2006).

Interactions among these different classes of organisms can make food webs and ecological processes complex, and spatial habitat arrangement and connectivity within wetlands increases that complexity (e.g., Gosselink and Turner 1978, Lugo 1990, Mitsch and Gosselink 2006). Wetland habitats that can support fish and other aquatic organisms consist of varying size patches connected by different size conduits. Organism movement among those patches (Eadie and Keast 1984, Turner 1988, Jude and Pappas 1992) and population changes provide much of the dynamics of wetland communities. This interconnected mosaic of habitat patches within the landscape fits the definition of a metacommunity (Hanski and Gilpin 1997, Hubbell 2001, Holyoak et al. 2005, Howeth and Leibold 2010a, Howeth and Leibold 2010 b, for example).

The status of aquatic organisms in MWC is poorly known and no measures of biological health are available to identify areas in need of improvement or protection. Which species are present, where they are found, and what constitutes distinct biotic assemblages are unknown for aquatic invertebrates, fish, or birds in the MWC. Neither do we know which environmental conditions significantly influence those biotic assemblages and how they are associated with each other and their habitats. A better understanding of how wetland communities are structured and function is critical to achieving MWC management goals, which include provision of habitat to support the annual life cycles of migratory and indigenous wildlife (Montezuma National Wildlife Refuge 2008). This study was designed to describe and quantify the structure of the aquatic community within the Montezuma National Wildlife Refuge and examine mechanisms that operate at a variety of scales to maintain that structure. Fish, birds, and aquatic invertebrates were selected for this study because of their sensitivity to environmental conditions and value to wetland managers (Karr 1981, Harris et al. 1983, Hilsenhoff 1987). These will be referred to as "major taxa" throughout this paper. Examining these major ecosystem components simultaneously can elucidate important factors maintaining community structure and ecological function. My objectives were to 1) identify and quantify significant patterns of wetland community structure on several trophic levels in relation to key elements of the physical and biological environment and 2) present evidence for processes and conditions that explain the community structure, including evaluation of four paradigms of metacommunity dynamics: Neutral Model, Patch Dynamics, Species Sorting, and Mass Effects (Leibold et al. 2004). I hypothesize that significant spatial structure exists for each class of organism and that strong environmental influences will highlight a Species Sorting type metacommunity in this wetland system.

\section{METHODS}

Wetland community structure was determined by measuring distinct spatial and temporal differences in diversity of aquatic assemblages, their species compositions and relative abundances, and their relationships to habitat conditions. I chose three different features of species assemblages to use as measures of similarities and differences: 1) abundances among taxa, 2) taxonomic composition (identity), and 3) diversity. While relative abundances among species does not explain all mass and energy flow through each component of a community (sizedependent physiological rates, productivity, and other processes are important), they provide an indication of how ecological activity is distributed among taxa. Taxonomic identity provides information about the role (niche) of each species or taxon within the community and helps us understand potential interactions among species and groups. Diversity provides a single number that is a well-known measure of abundance and composition (although not taxonomically specific) that can be used to compare assemblages. These species assemblages are embedded within broader-scale habitat units that have their own local conditions but also fit within a larger network of interconnected habitat patches. Leibold et al. (2004) offered four paradigms to help explain metacommunity dynamics, each placing different emphasis on habitat heterogeneity, differences among species and associated environmental limits, and dispersal abilities. Patch Dynamics explains species coexistence by a balance between competitive and dispersal abilities and assumes habitat patches are homogeneous and distributed uniformly. Hubbell's (2001) Neutral Model assumes that all species are functionally the same, including dispersal ability, and metacommunity dynamics occur by ecological drift within a matrix of homogeneous habitat patches. Mass Effects emphasizes moderate dispersal in a Source-Sink dynamic as the primary mechanism of metacommunity dynamics (Shmida and Wilson 1985). Species Sorting depends on species niche distinctions and emphasized changes in community structure along environmental gradients (Whittaker 1972); local environmental conditions dictate species occurrence. The latter two paradigms allow for heterogeneous habitats. As Falke and Fausch (2010) point out, there is, as yet, no stringent test of these different paradigms, but emphasis on spatial vs. environmental factors can reveal different metacommunity types. I evaluate the evidence for each as they apply to the classes of biotic assemblages in the Montezuma Wetlands Complex.

\section{SITE CHARACTERISTICS}

The Montezuma Wetlands Complex once contained over 16,000 hectares of contiguous wetland located on the Seneca River (a major component of one of Lake Ontario's largest tributaries). Loss of much of this wetland stimulated establishment of the Montezuma National Wildlife Refuge and wetland restoration projects in the late 1930s to protect the remnant for waterfowl and other wildlife. State and Federal agencies continue to acquire lands (presently $>14,000$ ha) within the MWC, which is now a diverse mosaic of land and water critical for both migratory and nonmigratory wildlife. However, the quality of aquatic and wetland habitats and their connectivity within the MWC varies considerably. Some areas have not been altered by farming or industrial activity for half a century or more, others have been farmed intensively; roads and the Erie Canal separate some sections from others. 


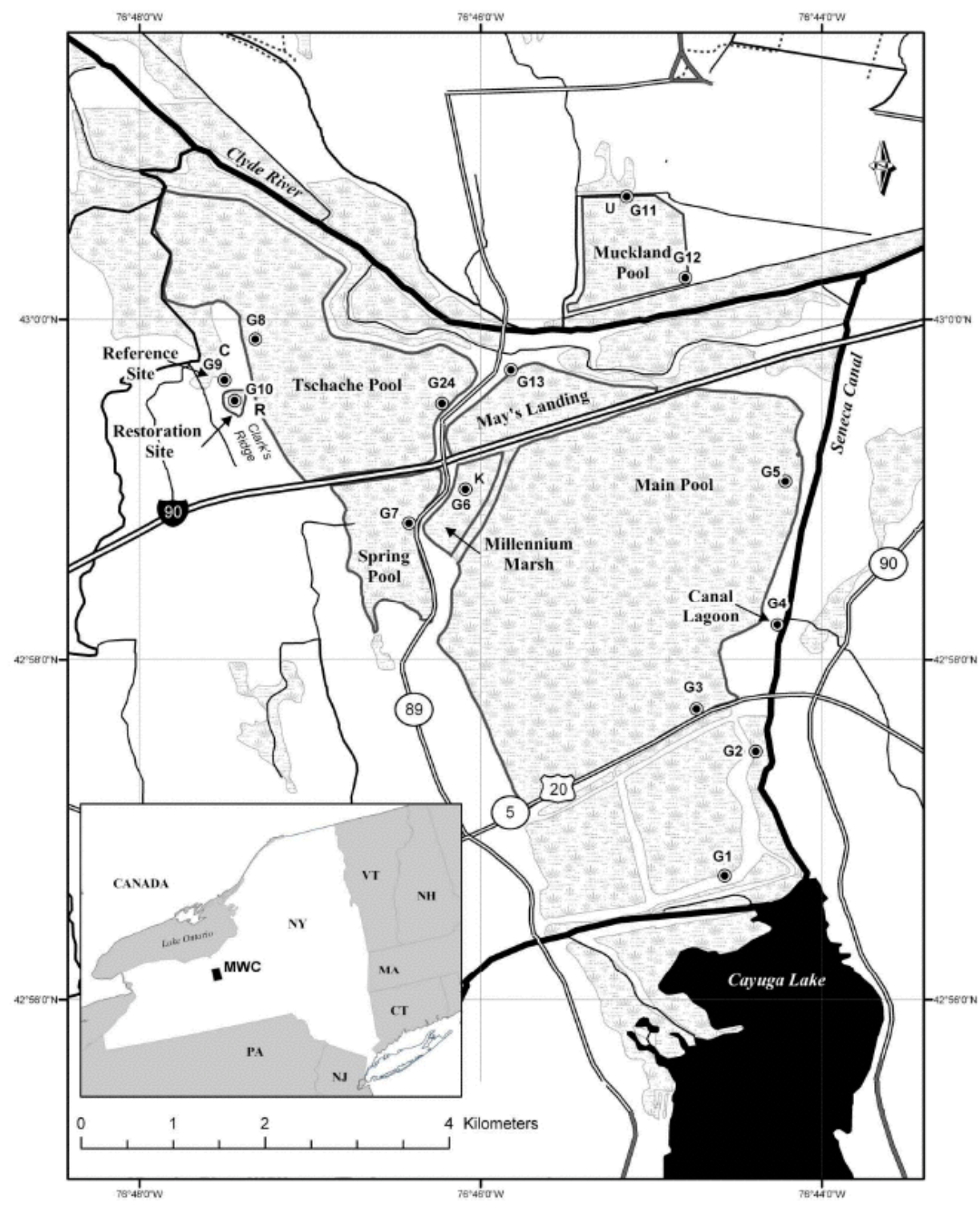

Fig. (1). Map of sample locations and water body spatial orientation. The site labeled R and G10 is the Clark's Ridge restoration site. The site labeled C and G9 is the Clark's Ridge reference site. K marks the location of Millennium Marsh sites collected in 2000 and U marks the location of muckland sites collected in 2000 before flooding. All labels beginning with G indicate the locations of other Stage 2 sample sites.

The MWC is located in Central New York, USA, at the mouth of Cayuga Lake and along the Seneca River (Fig. 1). The Montezuma National Wildlife Refuge is a major component of the MWC and the area where all sampling occurred. In general, the area has a cool, wet climate, with several months of sub-freezing temperatures in winter and periods of high summer temperatures $\left(>35^{\circ} \mathrm{C}\right)$. Samples were collected in two temporal stages. Stage 1 (1996 - 1999) was focused on comparing a small restored wetland with a reference site and was conducted in an isolated area, known as Clark's Ridge (CR) (McKenna 2003a); Stage 1 research included extensive measurements of system productivity. In Stage 2 (2000 - 2002), sampling was expanded to include the full range of habitats within the MNWR (Fig. 1, locations beginning with ' $G$ ', ' $\mathrm{K}$ ', or ' $U$ '). One sampling area included a large field that was used for muck farming (fertilizer and pesticide intensive) for many years; this site was prepared for restoration in 2000 , but not flooded until the following year (Fig. 1, sites beginning with U). In 2001, ten additional sites were selected randomly from a grid of cells laid over the refuge. Accessible wetland locations closest to the randomly selected points were chosen as sample sites; I also continued to sample the sites from Stage 1. Thus, the data set includes samples from 22 different sites, representing a wide range of habitats within the refuge and time series of collections at several locations. The large and medium pool habitats contained multiple sample sites and several sites represented ditch habitat (Fig. 1). Sampling was roughly proportional to frequency of habitat patch size within the refuge; repeated samples of fish (72), aquatic invertebrates (47), and birds (109) were collected over the study period.

Surface area of each sample site water body (Habitat Area) was determined by use of a Geographic Information System (ArcGIS 9 (ESRI, Redlands, California, USA)), based on the 1:100,000 scale National Hydrography Dataset. The sampled habitats ranged from drainage ditches $<0.2$ ha 
Table 1. Site Codes, Water Body Size, Spatial Orientations, and Size-Connectivity Index (SCI) Values for each Sampled Water Body. See Fig. (1) for Site Locations. Size Rank Corresponds to General Habitat Types of Large Pool (3), Medium Pool (2), and Ditch-like (1), but the CR Restoration and Reference sites were Small, Isolated Pools

\begin{tabular}{|c|c|c|c|c|c|c|c|}
\hline Water Body & Map Location & $\begin{array}{l}\text { Distance from } \\
\text { Source (Km) }\end{array}$ & Distance Rank & Area (ha) & Size Rank & $\begin{array}{l}\text { Number of } \\
\text { Connections }\end{array}$ & SCI Index \\
\hline Main Pool (M.P.) & G5 & 0.0 & 3 & 689.7 & 3 & 3 & 27 \\
\hline Millennium Marsh (M.M.) & $\mathrm{K}^{1}, \mathrm{G} 6$ & 1.1 & 1 & 0.5 & 1 & 2 & 2 \\
\hline Spring Pool (S.P.) & G7 & 1.5 & 1 & 34.9 & 2 & 1 & 2 \\
\hline Canal Lagoon (Lag.) & G4 & 0.1 & 3 & 0.2 & 1 & 1 & 3 \\
\hline Refuge Entrance Pool (G3) & G3 & 0.9 & 2 & 0.3 & 1 & 1 & 2 \\
\hline Pool S of Rt. 5/20 (G2) & $\mathrm{G} 2$ & 1.6 & 1 & 0.1 & 1 & 2 & 2 \\
\hline G1 ditch (G1) & G1 & 2.3 & 1 & 0.8 & 1 & 1 & 1 \\
\hline Mays Landing Pool (M.L.) & G13 & 0.1 & 3 & 38.5 & 2 & 2 & 12 \\
\hline Muckland Pool (Muck.) & $\mathrm{U}^{1}, \mathrm{G} 11, \mathrm{G} 12$ & 0.3 & 3 & 87.7 & 2 & 1 & 6 \\
\hline Tschache Pool (T.P.) & $\mathrm{G} 8, \mathrm{G} 24$ & 0.2 & 3 & 354.5 & 3 & 1 & 9 \\
\hline Restoration Site (Rest.) & $\mathrm{R}^{2}, \mathrm{G} 10$ & 3.2 & 1 & 0.2 & 1 & 0 & 0 \\
\hline Reference Site (Cont.) & $\mathrm{C}^{2}, \mathrm{G} 9$ & 3.2 & 1 & 0.3 & 1 & 0 & 0 \\
\hline
\end{tabular}

${ }^{1}$ samples collected in 2000 - pre-flood period for Muckland Pool were analyzed as Ditch-like habitat.

${ }^{2}$ samples collected in $>2000$ at Clark's Ridge (31).

in area to large, regulated pools nearly 700 ha (Fig. 1, Table 1) and all were shallow $(\leq 1.5 \mathrm{~m})$. Connectivity among these sites varied from direct connections to main pools or the Clyde River (the main tributary of the Seneca River) to complete isolation from surface flows (e.g., CR sites). Aside from that described above, little active management was applied to these pools. In some years, the largest (Main Pool, Tschache, and Mays Landing) were drawn down in the fall to provide enhanced mudflat habitat for migrating shorebirds. During this study only Tschache Pool was drawn down and that overlapped with fieldwork only in May 2001 (those samples were excluded from inter-site analyses).

\section{SIZE-CONNECTIVITY INDEX}

A Size-Connectivity Index (SCI) was constructed to provide a measure of the combined condition of size, proximity, and connectedness for the water body network. This is an index of the difficulty an aquatic organism hypothetically faced when traveling via water courses from the largest pool (Main Pool) or Clyde River to colonize (or re-colonize) any sample site within the study area. Use of the largest pool or river as the starting point is intended to indicate the colonist source habitats, those likely to be least disturbed by common environmental stresses (e.g., thermal or desiccation stress) and to contain the most extensive refuges from such events. I hypothesized that severely stressed habitats would be re-populated from these areas or an intermediate refuge along the pathway from that point to the affected site, forming a Source-Sink dynamic. This index allowed me to examine the effects of spatial orientation of the network of streams and canals on community structure. The index was constructed as the product of ranked values of relative size, dispersal distance, and connectivity.

$\mathrm{SCI}=\mathrm{S} \cdot \mathrm{D} \cdot \mathrm{C}$ where $\mathrm{S}$ is the size rank of the sample site water body (large $=3$, medium $=2$, and small $=1), \mathrm{D}$ is distance class from the sample site to the nearest edge of the Main Pool or Clyde River (whichever was closest) $(<0.5 \mathrm{~km}=3,0.5-1.5 \mathrm{~km}=$ 2 , and $>1.5 \mathrm{~km}=1)$, and $\mathrm{C}$ is the number of conduits $(0-3)$ between the sample site and the next water body downstream along the path to the Main Pool (or River). This index ranged from 0 to 27, with large values indicating large pools located close together with multiple connections. Zero indicates no surface water connection between the site and the Main Pool (or River). The Main Pool sample sites were assigned the maximum values for each metric (Table 1).

\section{PHYSICOCHEMICAL MEASUREMENTS}

A suite of ecosystem characteristics to which aquatic organisms are known to respond (e.g., water chemistry, landscape characteristics, and biotic populations) was sampled each time biotic samples were collected, typically monthly (Stage 1, see 31 ) or bimonthly (Stage 2 ). Water quality at each site was characterized by measurements of temperature $\left({ }^{\circ} \mathrm{C}\right)$, dissolved oxygen (D.O.) (mg/l), conductivity $(\mu \mathrm{S} / \mathrm{cm}), \mathrm{pH}$, and turbidity (NTU) collected during each sampling event, using Pinpoint meters or a YSI sonde (model 6600-D). A water sample was also collected during each sampling event and frozen for laboratory analysis of 23 elements by inductively coupled plasma spectrophotometry (values reported in ppm). Water depth was measured to the nearest centimeter each time samples were collected. Bottom substrate was collected and analyzed for grain-size and organic content. Sediment grain-size distribution was determined from ovendried samples by use of nested sieves and transformed to a modified Wentworth scale (Wentworth 1922); a weighted mean grain-size was used during data analysis. Organic content (OM) was determined as the proportion of mass of the dried sample remaining after incineration in a muffle furnace at $550^{\circ} \mathrm{C}$ for eight hours. 


\section{AQUATIC COMMUNITY SAMPLING}

Bird assemblages were quantified by 5-minute point counts conducted first during each sampling event (to minimize effects of disturbance). Birds were identified to species using $8 \mathrm{x}$ binoculars or by voice identification. Only aquatic birds were used in this study, and they are here defined as those that typically feed in water (e.g., ducks and geese and long-legged waders), but also include a few passerines that are intimately associated with and indicative of wetland and marsh vegetation (e.g., Marsh Wren [Cistothorus palustris] and Swamp Sparrow [Melospiza georgiana]).

Fish were collected with a $6.1 \mathrm{~m} \times 1.8 \mathrm{~m}$, small-mesh $(0.3 \mathrm{~cm})$, center-bag seine applied in an encircling manner and set such that the fish were not disturbed before closure, then the wings were hauled together to force fish into the bag (McKenna 2003a). The area swept clear on each set was approximately $3 \mathrm{~m}^{2}$, and each sample involved two net sets. After enumeration and identification to species of each fish caught, the standard lengths of 20 individuals of each species were measured to the nearest millimeter. A standardized index of fish abundance, based on catch per unit effort (CPUE) was calculated by adjusting the number of fish caught by each net set to a standard area of $100 \mathrm{~m}^{2}$ and then summing the catches from both seine hauls. Herptofauna and crayfish were also collected as by-catch in the seines; they were counted and recorded.

Aerial insects and other aquatic invertebrates are two major components of wetland assemblages. Aquatic insects are a dominant component of wetland systems and many remain on the bottom or vegetation surfaces until reaching a dispersal stage in their life cycle; this is often a brief adult stage (Hynes 1972, Merritt and Cummins 1984, Peckarsky et al. 1990). Aerial insects may feed throughout the water column, but disperse to other habitats at any time by flying. Other aquatic invertebrates, like zooplankton (e.g., cladocerans), are typically transported along water courses or by birds (Schlichting 1960, Proctor and Malone 1965). Two techniques were used to collect aquatic invertebrates from areas undisturbed by fish sampling. A $5-\mathrm{cm}$ deep benthic core $(10-\mathrm{cm}$ diameter) was used to collect infauna and epifauna from shallow soft-bottom habitat (McKenna 2003a). Three standard sweeps of a fine-mesh $(500 \mu \mathrm{m}) \mathrm{dip}$ net were used to collect aerial insects and those associated with aquatic vegetation. These samples were sieved $(500-\mu \mathrm{m}$ screen), preserved in $70 \%$ ethanol, and returned to the laboratory for identification and quantification. Specimens were identified to the lowest possible taxon. However, many specimens were not sufficiently intact to identify to genus. Thus, family-level identification was used in this analysis. Aerial Insect and other aquatic invertebrate (hereafter referred to as Aquatic Invertebrates) assemblages were analyzed separately due to the differences in habitat occupied, collection gear used, and some important life history differences. Some groups occurred in both gear types, notably cladocerans, but only taxa that disperse by flight were included in the Aerial Insect group. Each major taxon was given a mobility rank $(1=$ least to $4=$ most $)$ according to the general ability of its constituent species to quickly disperse and recolonize available habitat patches throughout the aquatic habitat network.

\section{ANALYSES}

The Shannon-Weaver information index (H') (Shannon and Weaver 1949) was used to measure diversity because it is one of the most commonly applied and well-understood diversity measures. Species (or taxon for invertebrates) richness (the number of distinct taxa) was also determined at spatial scales from the local sample up to the full metacommunity. The metacommunity is here defined as all trophically similar individuals and species in a regional collection of local communities (Hubbell 2001), but speciesspecific identity is maintained. Metacommunity conditions are represented by the mean of all local assemblages of a given major taxon. The distribution of abundance among species is a measure of community structure and has been modeled in a number of ways (Fisher et al. 1943, Preston 1948, Ricklefs and Miller 2000). Hubbell (2001) shows that as local communities become more isolated from the rest of a metacommunity, rare species become rarer and common species become more common. One result of this is that the species abundance distribution changes shape from geometric-like in the most isolated to log-series-like in a full metacommunity. In this study, the fit of species (or taxon) assemblages to both the log-series and geometric distributions was examined. These models apply well to a variety of organisms, including fish (Shepard 1984, Saila et al. 1996), and provide insight into the relative balance of common and rare species in an assemblage. Geometric distributions are typical of species-poor assembles, strongly dominated by a few of the most common species (Hubbell 2001, Fattorini 2005). The log-series distribution includes many rare species and is typical of assemblages in relatively large habitat patches and large scale systems (e.g., metacommunities) (Hubbell 2001). The fit of each species (or taxon) assemblage (containing $>3$ taxa) to the log-series distribution was tested using the LOGSRFIT program (Saila et al. 1996). Values of the $\mathrm{K}$ parameter less than 1.0 were considered to indicate a reasonably good model fit (Saila $e t$ al. 1996). Linear regression of log-transformed abundances by rank was used to determine fit to the geometric distribution (Fattorini 2005).

Bootstrapping cluster analysis was used to group samples with similar species (or taxa) assemblages or habitat similarities (noted above) and determine significant differences among those groups (Nemec and Brinkhurst 1988, McKenna 2003b). Abiotic data were standardized (mean $=0, \sigma=1)$ to eliminate differences in measurement units and range, and examined with cluster analysis to identify physicochemically distinct habitats (Fig. 2). Those general groupings were used initially to arrange biotic samples into meaningful replicate groups. For example, samples from sites G1 and G6 were grouped together as replicate representatives of small, ditch-like habitat (Fig. 1). To allow for greater potential differentiation among the biotic assemblages, samples of the connected pools (e.g., G2, G3, and G5) and Stage 2 muckland (post-flood) sites (G11 and G12) were maintained as separate replicate groups. For each biotic analysis, (i.e., major taxon: bird, fish, invertebrate) data were transformed by $\ln (x+1)$ to reduce the influence of exceptionally abundant taxa. Each cluster analysis used the Bray-Curtis similarity coefficient and UPGMA linkage method (Boesch 1977, McKenna 2003b). 


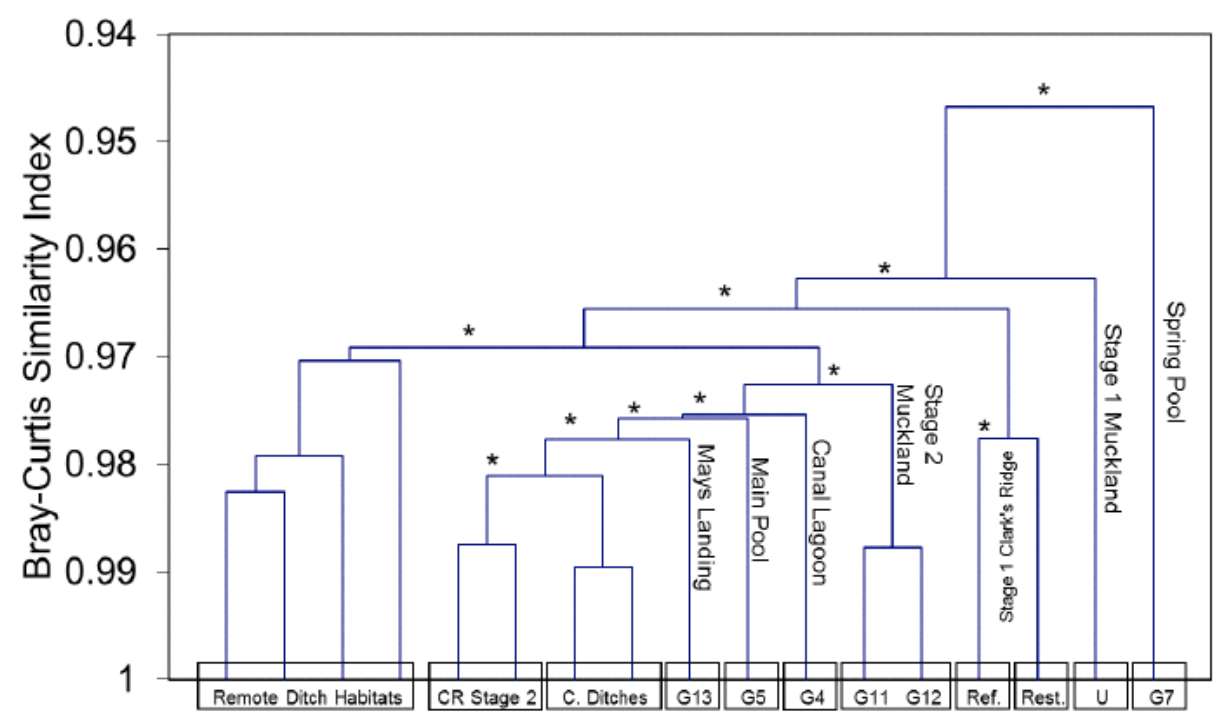

Fig. (2). Dendrogram of results of clustering standardized abiotic samples. Each significantly distinct group of samples is contained within an open box. Cluster labels can be found on the Fig. (1) map; Remote Ditch Habitats include samples at G1, G6, G24, and K; CR Stage 2 samples were at Clark' Ridge; Ditches includes samples at G2 and G3; Ref. samples are from the CR Reference site; and Rest. Samples are from the CR Restoration site. Each linkage joining two significantly distinct groups is indicated with an asterisk *. Bray-Curtis similarity is shown along the ordinate.

One thousand bootstrap samples were generated to test each linkage for significance $(\alpha=0.05)$.

Canonical correspondence analysis (CCA) was performed using the CANOCO program (ter Braak 1988) to identify gradients within the biological data and relate them to abiotic factors. Variables were added by the forward selection process until their contribution was not significant, based on results of the Monte Carlo permutation test (using 499 permutations) (ter Braak 1986). Thus, only the most important abiotic factors were included in the analyses (Jongman et al. 1995). Results of cluster analysis were then superimposed on the ordination to provide significant assemblage demarcations within the ordination hyperspace. This greatly aids in CCA interpretation, providing significant units (perceived by the organisms) along natural gradients. I examined the relative weights of significant environmental gradients (including biotic) to evaluate the emphasis on environmental conditions vs. spatial factors. Upper case names are used in the text to identify environmental gradients, major taxa, and habitat types.

The S-Plus statistics program (S-Plus 6 for Windows. Insightful Corporation, Seattle, Washington) was used to fit regressions and perform analysis of variance (ANOVA) to test for significant differences of univariate relationships among biotic assemblages identified by interpretation of the multivariate analyses. A Bonferroni multiple comparison test was used to determine the differences among groups when ANOVA detected significant differences (Zar 1989).

\section{RESULTS}

Aquatic assemblages were composed of numerous taxa from each group. Aquatic Invertebrates were abundant and collected from all sites (16 Stage 1 samples and 31 Stage 2 samples); more than 50 families were represented. Cladocera were numerically the most abundant taxon, followed by Chironomidae, Gastropoda, and Oligochaeta. Crayfish
(Cambaridae) were also present, particularly at the CR reference site. More than 10,000 Aerial Insects, represented by 45 families, were collected (8 Stage 1 samples and 33 Stage 2 samples); only flying insects (Aerial Insects) were retained for analysis in this group. Aerial Insects occurred in both stages at all sites, except for the canal lagoon (G4). Seventy-two percent of the assemblage was composed of midges (Chironomidae, 25\%) and bugs (Veliidae, 18\%); five other taxa each accounted for $2 \%-7 \%$ of total abundance. More than 13,000 fish of 21 species were collected (40 Stage 1 samples and 32 Stage 2 samples); they occurred at all sites, except for the CR restoration site. More than 10,000 amphibians (seven species) were collected, most of which were tadpoles of the Ranidae family, and were the primary vertebrates present at the $\mathrm{CR}$ restoration site. Eastern painted turtle (Chrysemys picta) (three individuals) was the only reptile species collected. Only fish and tadpoles were used in this study and will be referred to as Aquatic Vertebrates hereafter. Fathead minnows (Pimephales promelas) and tadpoles (Rana spp. Linnaeus) were most abundant and accounted for $78 \%$ of the Aquatic Vertebrate community. However, $97 \%$ of fathead minnows and $99 \%$ of tadpoles were collected at the isolated pools of the CR sites. Nearly 2,000 Aquatic Birds of 39 species were observed (73 Stage 1 samples and 36 Stage 2 samples). Great Blue Heron, Mallard (Anas Platyrhynchus), American Black Duck (Anas rubripes), Double-crested Cormorant (Phalcrocorax auritus), and Canada Goose (Branta canadensis) were the most common species. Fifteen of the Aquatic Bird species are piscivorous and were observed in $88 \%$ of sites (absent in sites G2 and G3).

\section{DISTINCT ASSEMBLAGES AND MAJOR HABITATS}

Aquatic habitat patches were not uniform in size $(0.1-$ $690 \mathrm{ha})$ or separation distance $(0.1-2.3 \mathrm{~km})$ and abiotic conditions differed spatially and temporally within the study area; nearly all sites were environmentally distinct (Fig. 2). However, ditch-like habitats grouped together and CR sites 

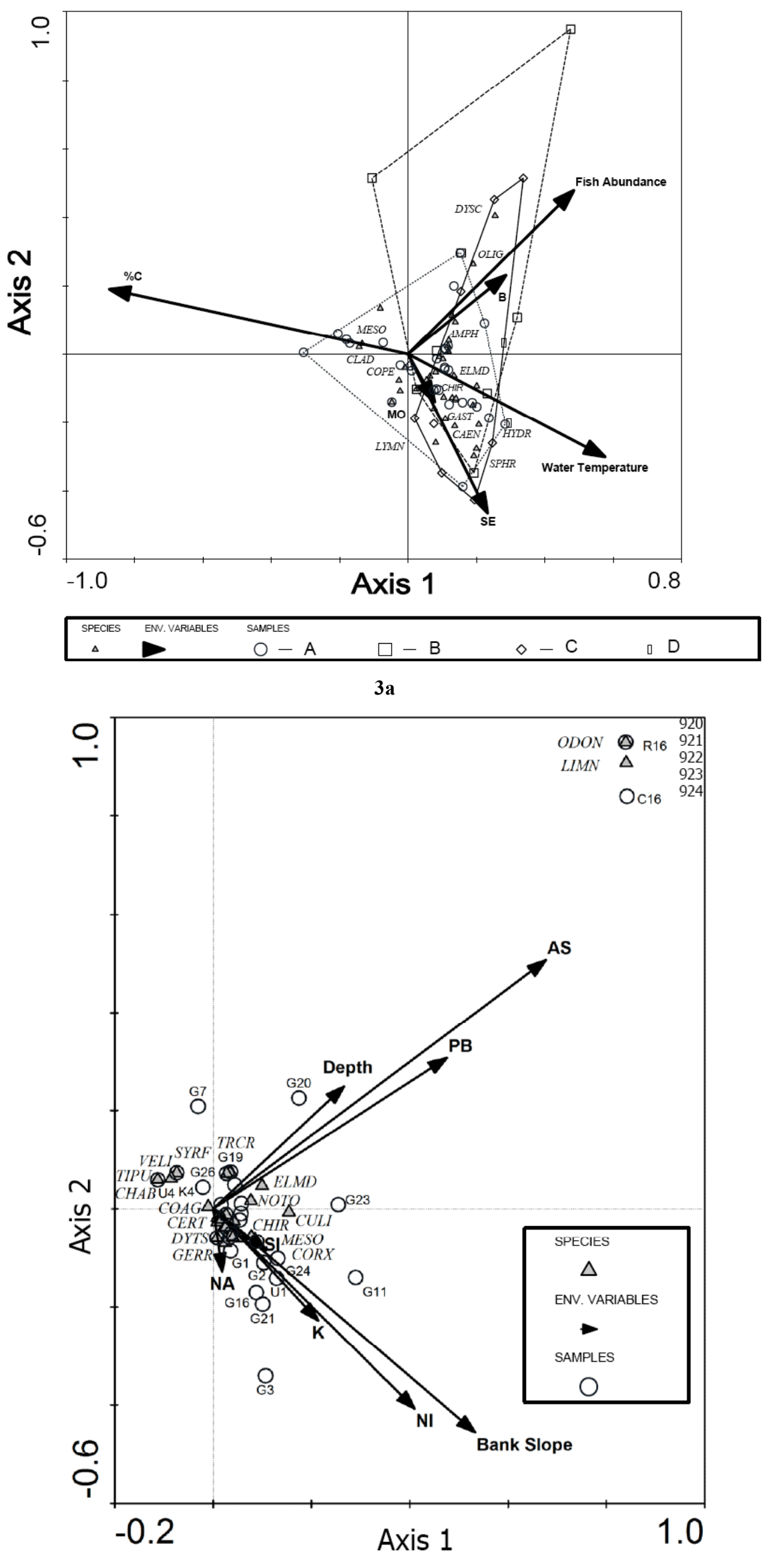

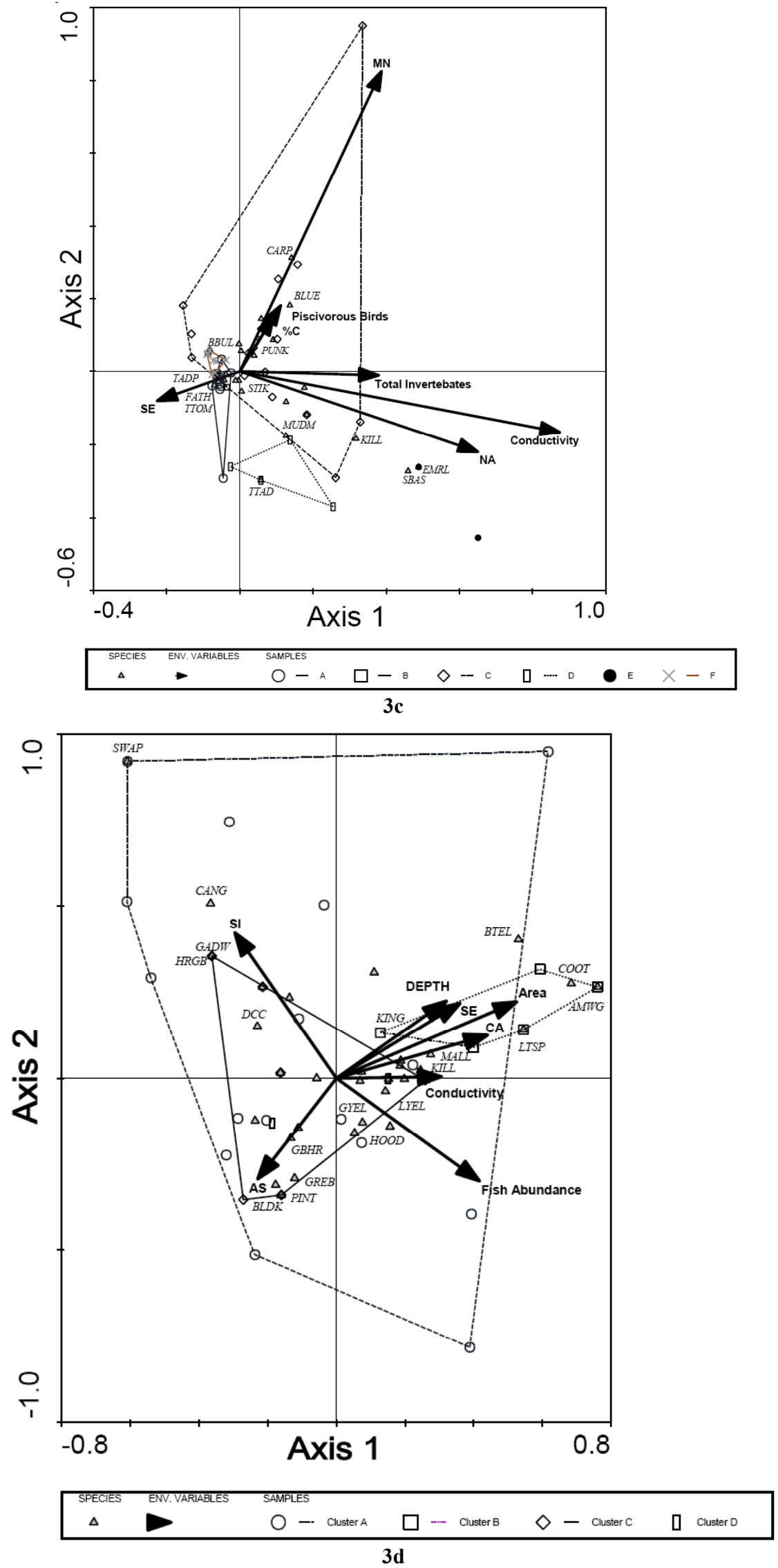

Fig. (3). Axes 1 and 2 of CCA triplots for a.) Aquatic Invertebrate assemblages, b.) Aerial Insect assemblages, c.) Aquatic Vertebrate assemblages, and d.) Aquatic Bird assemblages. Environmental gradients are indicated by arrows. Values increase in the direction of the arrows and the length of each arrow is an indication of the influence of that variable on the biotic assemblage. Each taxon optimum is 
indicated by an open triangle. Sample labels match those shown in Fig. (1). Cluster designations match those of Fig. (6). Samples of each distinct Aquatic Invertebrate assemblage (cluster) are enclosed within polygons; open circle $=$ General Assemblage, open square $=\mathrm{CR}$ reference assemblage, open diamond $=$ Stage $1 \mathrm{CR}$ restoration assemblage, and open rectangle $=$ Stage 2 CR restoration assemblage. Taxon codes: $\mathrm{AMPH}=$ Amphipoda, $\mathrm{CAEN}=$ Caenidae, $\mathrm{CHIR}=$ Chironomidae, $\mathrm{COPE}=$ Copepoda $, \mathrm{CLAD}=\mathrm{Cladocera}, \mathrm{DYSC}=\mathrm{Dytiscidae}$, ELMD = Elmidae, GAST = Gastropoda, HYDR $=$ Hydrachnidae, LYMN $=$ Lymnaeidae, MESO $=$ Mesoveliidae, OLIG $=$ Oligochaeta, and $\mathrm{SPHR}=$ Sphaeriidae. Aerial Insect Taxon codes, in addition to those of Aquatic Invertebrates: CERT $=$ Ceratopogonidae, $\mathrm{CHAB}=\mathrm{Chaoboridae}, \mathrm{COAG}=\mathrm{Coenagrionidae}, \mathrm{CORX}=$ Corixidae, $\mathrm{CULI}=\mathrm{Culicidae}, \mathrm{GERR}=$ Gerridae$, \mathrm{LIMN}=\mathrm{Limnephilidae}, \mathrm{NOTO}=$ Notonectidae, ODON=Odonata, SYRF=Syrphidae, TIPU=Tipulidae, TRCR=Tricorythidae, VELI = Veliidae. Samples of each distinct Aquatic Vertebrate assemblage (cluster) are enclosed within polygons; open circle $=$ Cluster $\mathrm{A}$, open square $=\mathrm{Cluster} \mathrm{B}$, open diamond $=$ Cluster $\mathrm{C}$, open rectangle $=$ Cluster $\mathrm{D}$, solid circle $=$ Cluster E, and $\mathrm{X}=$ Cluster F. Species codes: BBUL $=$ brown bullhead, BLUE $=$ bluegill, $\mathrm{CARP}=$ common carp, EMRL $=$ emerald shiner, FATH $=$ fathead minnow, GFSH $=$ goldfish, GOLD $=$ golden shiner, KILL $=$ banded killifish, MUDM = Central mudminnow, PUNK = pumpkinseed, SBAS = smallmouth bass, STIK = brook stickleback, TADP $=$ tadpole spp., TTAD $=$ toad tadpole, and TTOM $=$ tadpole madtom. Samples of each distinct aquatic bird assemblage (cluster) are enclosed within polygons; open circle $=$ Cluster $\mathrm{A}$, open square $=$ Cluster $\mathrm{B}$, open diamond $=$ Cluster $\mathrm{C}$, and open rectangle $=$ Cluster D. Species codes: AMWG $=$ American Wigeon, BLDK = Black Duck, BTEL $=$ Blue-winged Teal, CANG $=$ Canada Goose, COOT $=$ American Coot, DCC $=$ Double-crested Cormorant, GADW = Gadwall, GBHR $=$ Great Blue Heron, GREB $=$ Pied-billed Grebe, GYEL = Greater Yellowlegs, HRGB $=$ Horned Grebe, HOOD $=$ Hooded Merganser, KILL $=$ Killdeer, KING $=$ Belted Kingfisher, LTSP $=$ Least Sandpiper, LYEL $=$ Lesser Yellowlegs, MALL $=$ Mallard, PINT $=$ Pintail, and SWAP $=$ Swamp Sparrow.

Table 2. Summary of Canonical Correspondence Analysis Results for each Major Taxon. Spp-Envl Corr. Indicates the SpeciesEnvironment Correlation for each Axis. Spp-Envl Var. Indicates the Cumulative Percentage of Variance in the SpeciesEnvironment Relationship that is Explained by Each Axis

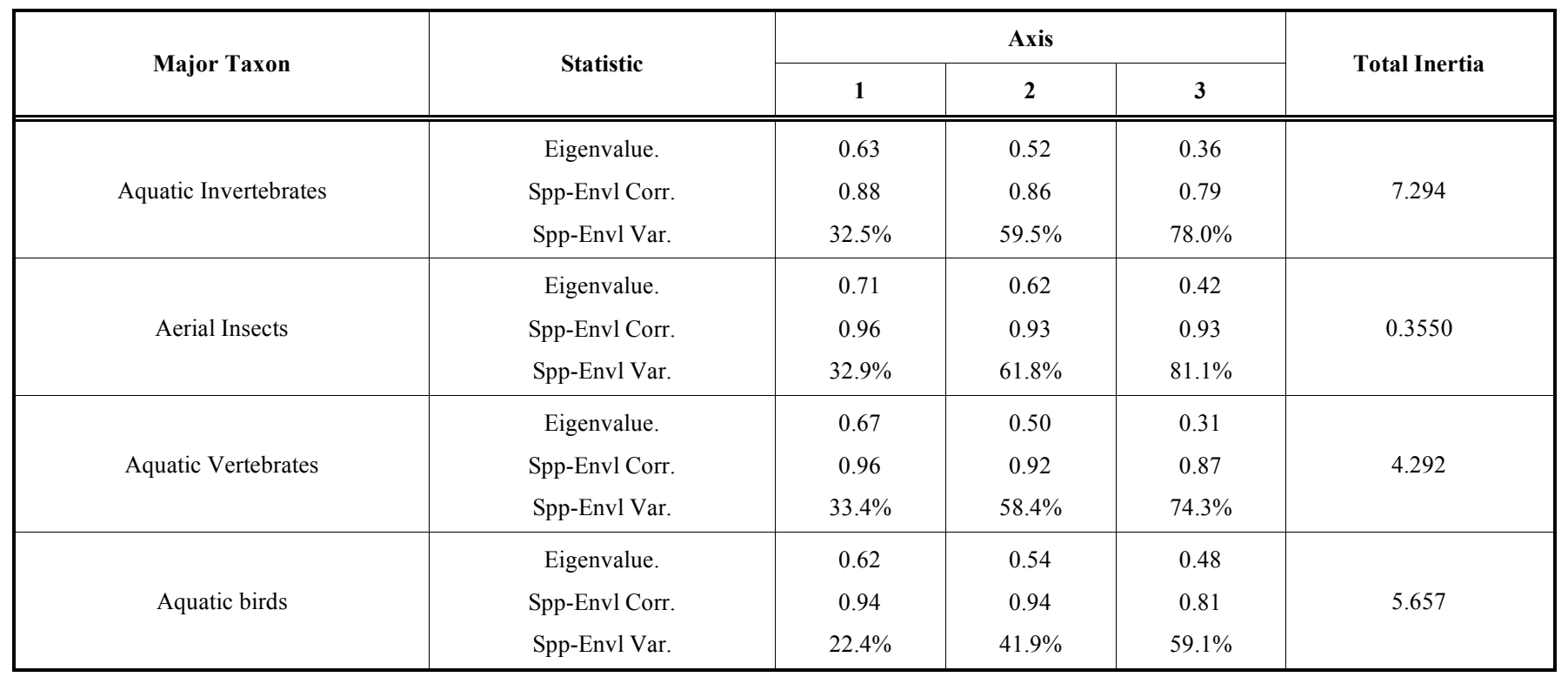

were distinct in Stage 1. All of the large, connected pools (except for Spring Pool [G7 and G20]) were different $(\mathrm{P}<$ 0.05 ), but more similar to each other than to other habitats. Concentrations of potentially toxic elements ( $\mathrm{Se}, \mathrm{As}, \mathrm{Cd}, \mathrm{Cr}$, and $\mathrm{Pb}$ ) were elevated at the $\mathrm{CR}$ sites, particularly during the dry conditions of Stage 1; chemical concentrations were dilute during the relatively wet Stage 2 period.

Spatial (and in some cases temporal), structure also existed among assemblages of most major taxa and relationships to environmental conditions were clear. Biotic cluster analyses showed that there was no significant structure among Aerial Insect sample assemblages, but identified as many as six distinct assemblage types within other major taxa. Ordination (CCA) revealed significant associations between biotic assemblages and from five to eight environmental factors (inflation factors were <5.0). The first three CCA axes explained $\geq 70 \%$ of taxaenvironmental variation (except for Aquatic Birds) and the taxa-environment correlation was $>78 \%$ for all groups
(Table 2). Each distinct taxon assemblage (i.e., cluster) was identifiable within the plane of the first two axes, with varying degrees of overlap near the origin (Fig. 3 a-d). The suite of important environmental variables consisted of different combinations of biotic and abiotic influences for each major taxon and included at least one biotic variable, except in the case of Aerial Insect. Aquatic Invertebrates and Aquatic Birds responded to Fish Abundance, while fish responded to both Total Invertebrates and Piscivorous Birds. Among the important abiotic variables, three major taxa responded to Conductivity, $\mathrm{Si}$, and $\mathrm{Se}$. Two major taxa responded to Water Temperature, Water Depth, As, and OM. The other influential variables were only important to a single major taxon.

Three major habitat types that persist among major taxa emerged from the direct gradient analysis and clustering results: 1) relatively large, well-connected pools [Large Pools], 2) small ditch-like habitats connected to the large pool network [Ditches], and 3) small, isolated pools 
Table 3. Alpha and Beta Diversity of each Major Taxon in each Major Habitat Type and Metacommunity. Mobility Rank is a Relative Measure of each Major Taxon's Ability to Disperse. Mean SCI is the average Size-Connectivity INDEX Value by Major Habitat Type. $\mathbf{N}$ is the Average Abundance of Individuals (Number/Standardized Collection) in each Major Habitat type. Taxa Richness Shows the Beta Taxa Richness Followed by the Mean Alpha Taxa Richness in each Major Habitat Type. Taxa Diversity shows the Beta Taxa Diversity Followed by the Mean Alpha Taxa Diversity in each Major Habitat Type

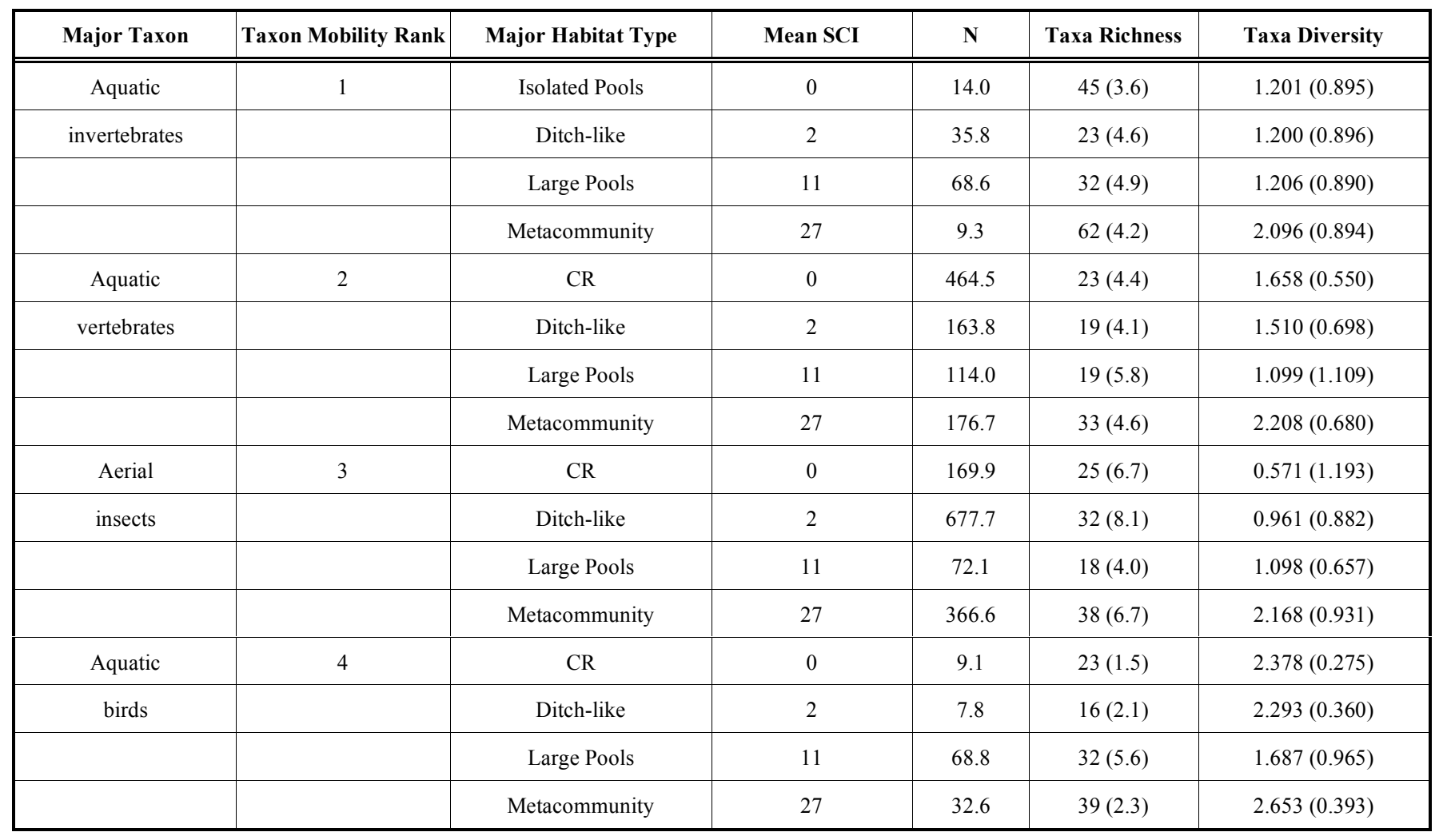

(comprised of the $\mathrm{CR}$ restoration and $\mathrm{CR}$ reference sites) [Isolated Pools]. The Large Pools included all sites $>1.0$ ha in area, the CR sites comprised the Isolated Pools, and all other sites were ditch-like habitat. Mean local animal abundance varied greatly among these major habitat types (Table 3). Aerial Insects were $2 x-9 x$ and fish $1.5 x-4 x$ more abundant in the smaller habitats (Ditches and Isolated Pools) than in the large, well-connected habitats (Large Pools). Aquatic Birds $(7.5 x-9 x)$ and Aquatic Invertebrates $(2 x-4 x)$ were more abundant in the large habitat than in the smaller habitats (Fig. 4). In general, common species were more common and rarer species more rare in the smaller, more isolated habitats than in the entire metacommunity, as expected for more isolated communities (Hubbell 2001).

\section{DIVERSITY AND THE SIZE-CONNECTIVITY INDEX}

Local assemblage diversity (i.e., alpha diversity, $\mathrm{H}_{\alpha}$ ) also varied among major habitat types and taxa (Table $\mathbf{3}$ ). The patterns of Aquatic Vertebrate and Aquatic Bird $\mathrm{S}_{\alpha}$ and $\mathrm{H}^{\prime}{ }_{\alpha}$ were similar (and opposite to Aerial Insect richness) with low values in the small habitats (Ditches and Isolated Pools) and higher values $(>1.5 \mathrm{x})$ in large habitats. Metacommunity $\mathrm{S}_{\gamma}$ is the total of all distinct taxa within the study area and $\mathrm{H}_{\gamma}{ }_{\gamma}$ is the associated diversity; both were always greater than for any major habitat or sample. BetaRichness $S_{\beta}$ (number of species in combined samples from each major habitat type) and beta-diversity $\mathrm{H}_{\beta}{ }_{\beta}$ (calculated as the difference between $\mathrm{H}_{\gamma}{ }_{\gamma}$ and $\mathrm{H}^{\prime}{ }_{\alpha}$ ) represent diversity at intermediate spatial scales, but did not consistently increased with SCI (Table 3). The $S_{\beta}$ generally increased from Ditches to Large Pools for major taxa, except for Aerial Insects. However, Aquatic Vertebrates and Aquatic Invertebrates were richer in Isolated Pools than the other major habitat types. The regional $(\beta)$ component of vertebrate diversity was larger than the local $(\alpha)$ component. However, local diversity $\left(\mathrm{H}_{\alpha}^{\prime}\right)$ accounted for most of the Aerial Insect diversity within the study area. The largest $\alpha$ to $\beta$ scale diversity increases occurred in the smallest habitats.

Regressions of alpha richness $\left(\mathrm{S}_{\alpha}\right)$ or diversity $\left(\mathrm{H}_{\alpha}{ }_{\alpha}\right)$ on the SCI index showed a range of responses (Table 4). Neither $\mathrm{S}_{\alpha}$ nor $\mathrm{H}^{\prime}{ }_{\alpha}$ of Aerial Insects were related to SCI. Aquatic Invertebrate $\mathrm{H}^{\prime}{ }_{\alpha}$ was also unrelated to $\mathrm{SCI}$, but $\mathrm{S}_{\alpha}$ was significantly influenced $(\mathrm{P}=0.03)$. Fish also displayed a mixed response to SCI, with $\mathrm{H}_{\alpha}^{\prime}$ showing a significant response $(\mathrm{P}=0.003)$, but none for $\mathrm{S}_{\alpha}$. In contrast, bird $\mathrm{H}^{\prime}{ }_{\alpha}$ and $\mathrm{S}_{\alpha}$ were strongly and positively affected by SCI. However, none of these relationships explained more than $38 \%$ of variation in the dependent variable.

The Large Pools were well connected to each other, more tenuously connected to Ditches, and disconnected from Isolated Pools; distinct taxa assemblages were associated with these different major habitat types (Table 5). Aquatic Invertebrate and Aquatic Vertebrate assemblages in Isolated Pools habitats were associated with lower SCI than that of the Large Pools and Ditches assemblages. Aquatic Bird assemblage structure matched a pattern of increasing SCI 

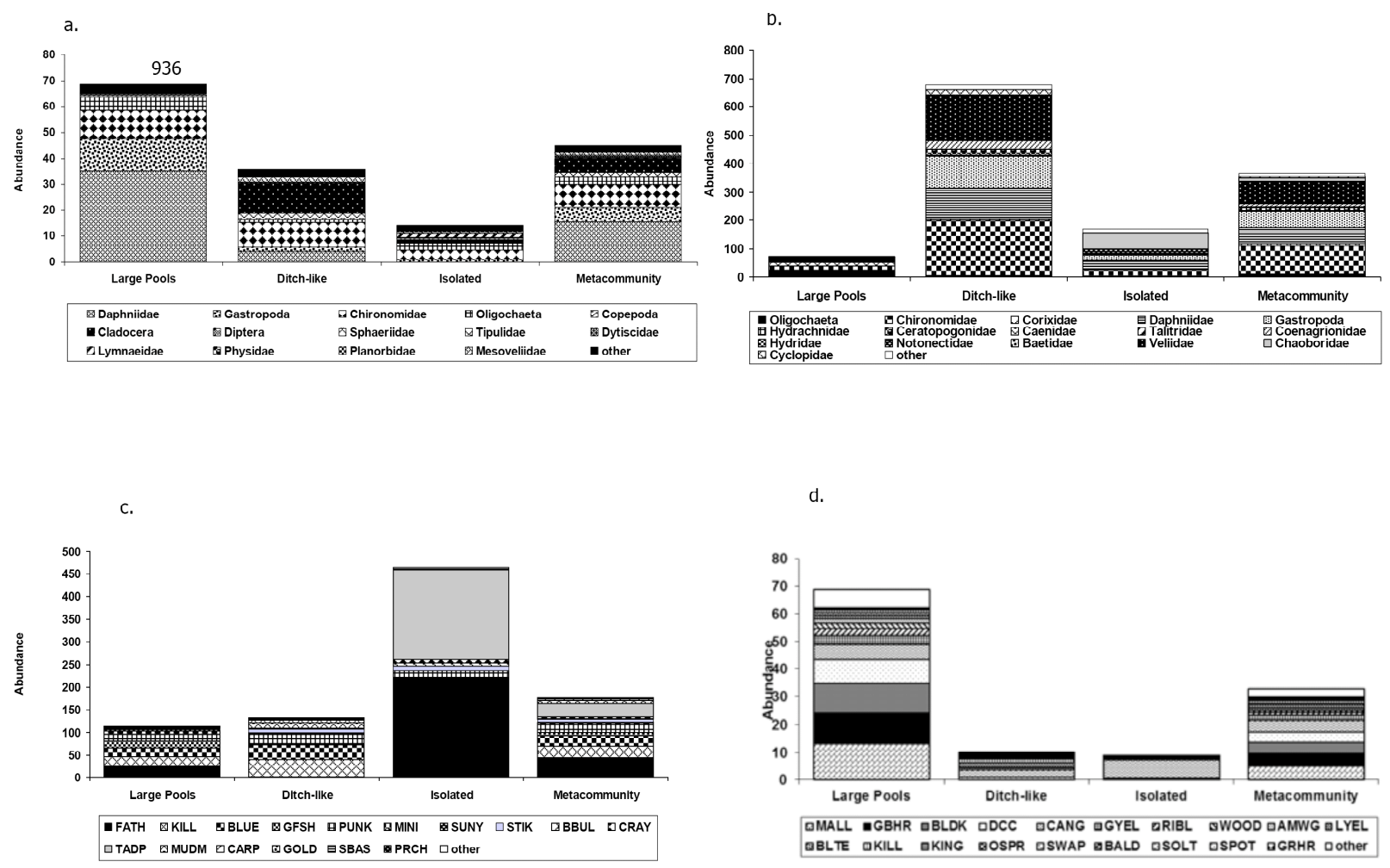

Fig. (4). Mean major taxa assemblages by major habitat type (i.e., Large Pools, Ditches, and Isolated Pools). Stacked bar chart shows abundance (height of bar segment) and species composition (pattern) of each assemblage, a.) Aquatic Invertebrates, b.) Aerial Insects, c.) Aquatic Vertebrates, and d.) Aquatic Birds. Species codes are given in Fig. (3) with the addition of SBAS $=$ smallmouth bass, PRCH $=$ yellow perch, BALD = Bald Eagle, OSPR = Osprey, SOLT $=$ Solitary Sandpiper, and SPOT = Spotted Sandpiper.

Table 4. Results of Regression Model Predicting Alpha Diversity ( $\mathrm{S}=$ taxa richness or $\mathbf{H}^{\prime}=$ Shannon-Weaver Index $)$ as a Function of Size-Connectivity Index (SCI). The Number of Samples (N), Parameter Estimate and Residual Standard Error (S.E.), F Statistic (F), Probability of Significant Regression (P), and Coefficient of Determination $\left(R^{2}\right)$ are Shown. $P$ Values $<0.05$ are Shown in Boldface

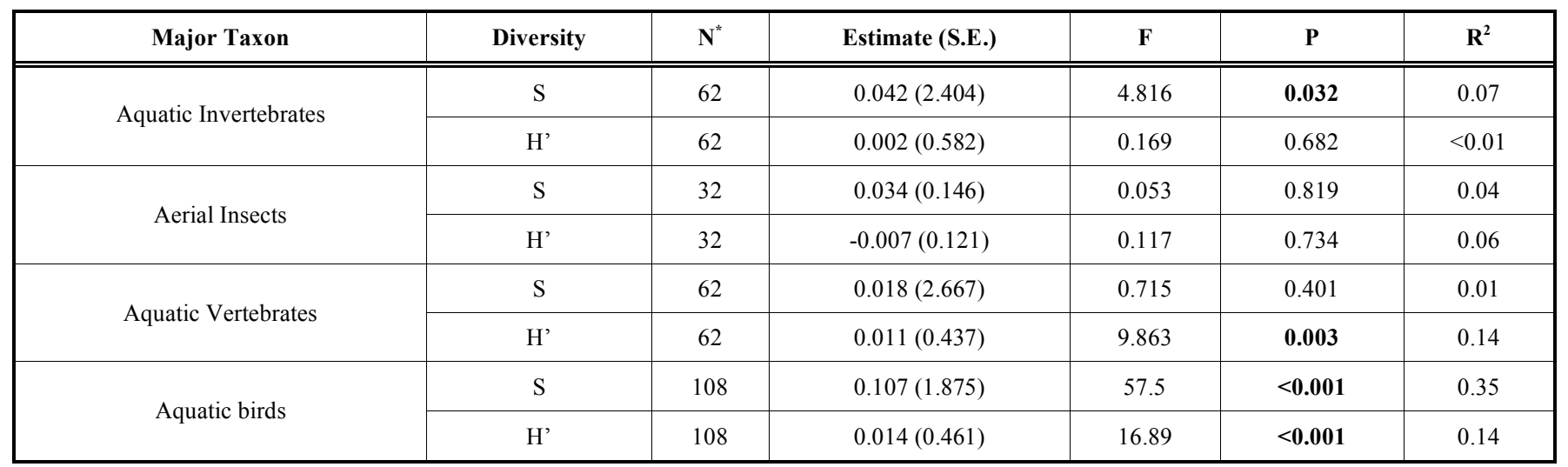

* Residual degrees of freedom $=\mathrm{N}-2$; regression degrees of freedom $=1$.

Table 5. Results of Anovas comparing SCI index values Among Distinct Assemblages for Each Major Taxonomic Group. The Mean SCI Value (and Number of Sample Assemblages) is Shown for Each Major Taxon. The Anova F Statistic and Probability (P) of Significant Differences Among Assemblages are Provided. Summary of the Bonferroni Multiple Comparison Test Indicates which means were different from others; I = Isolated Pools, D = Fringe/Ditches, and L = Large Pools

\begin{tabular}{|c|c|c|c|c|c|c|}
\hline \multirow{2}{*}{ Functional Group } & \multicolumn{3}{|c|}{ Major Habitat } & \multirow{2}{*}{ F-Statistic } & \multirow{2}{*}{ P } & \multirow{2}{*}{ Multiple Comparisons } \\
\cline { 2 - 6 } & Isolated Pools & Fringe / Ditches & Large Pools & & & \\
\hline \hline Aquatic Invertebrates & $0.0(34)$ & $3.0(17)$ & $10.3(12)$ & 34.33 & $<0.001$ & L $>$ D $>$ I \\
\hline Aerial Insects & $0.0(11)$ & $3.0(14)$ & $8.75(8)$ & 10.55 & $<0.001$ & L $>$ D, I \\
\hline
\end{tabular}


Table 5. contd...

\begin{tabular}{|c|c|c|c|c|c|c|}
\hline \multirow{2}{*}{ Functional Group } & \multicolumn{3}{|c|}{ Major Habitat } & \multirow{2}{*}{ F-Statistic } & \multirow{2}{*}{ P } & \multirow{2}{*}{ Multiple Comparisons } \\
\cline { 2 - 7 } & Isolated Pools & Fringe / Ditches & Large Pools & & & \\
\hline \hline Aquatic Vertebrates & $0.0(41)$ & $3.1(12)$ & $10.9(10)$ & 36.51 & $<0.001$ & L $>\mathrm{D}>\mathrm{I}$ \\
\hline Aquatic birds & $0.0(78)$ & $2.9(18)$ & $9.8(13)$ & 67.3 & $<0.001$ & L $>\mathrm{D}>\mathrm{I}$ \\
\hline
\end{tabular}

"Total ANOVA degrees of freedom is equal to number of sample assemblages - 1; among groups degrees of freedom is equal to the one less than the number of groups being compared.

Table 6. Goodness of Fit of Assemblages to the Log-Series Distribution. The Percent (and Number) of Sample Assemblages with K Parameter Values < 1.0 (Indicating Good Fit to the Log-Series Distribution) are Shown. K Parameter Values (and Number of Constituent Sample Assemblages) are Provided for Mean Assemblages by Distinct Cluster and General Habitat Type, for each Major Taxon

\begin{tabular}{|c|c|c|c|c|c|c|c|c|c|c|}
\hline \multirow{2}{*}{$\begin{array}{l}\text { Major } \\
\text { Taxon }\end{array}$} & \multirow{2}{*}{$\begin{array}{c}\text { Sample } \\
\text { Assemblages } \\
\%\end{array}$} & \multicolumn{6}{|c|}{ Mean Cluster Assemblage } & \multicolumn{3}{|c|}{$\begin{array}{c}\text { Mean General Habitat } \\
\text { Type Assemblage }\end{array}$} \\
\hline & & $\mathbf{A}$ & B & $\mathbf{C}$ & $\mathbf{D}$ & $\mathbf{E}$ & $\mathbf{F}$ & Large Pools & Fringe/Ditch & $\begin{array}{c}\text { Isolated } \\
\text { Pools }\end{array}$ \\
\hline Aquatic invertebrates & $46 \%(29)$ & $2.54(31)$ & $1.22(16)$ & $1.69(14)$ & $1.89(2)$ & -- & -- & $2.14(12)$ & $40.23(8)$ & $1.11(41)$ \\
\hline Aerial insects & $79 \%(26)$ & $1.12(26)$ & -- & -- & -- & -- & -- & $1.08(13)$ & $0.75(12)$ & $0.85(8)$ \\
\hline Aquatic vertebrates & $47 \%(30)$ & $0.45(23)$ & $0.10(4)$ & $0.28(15)$ & $0.38(5)$ & $0.60(2)$ & $1.31(14)$ & $0.28(19)$ & $0.81(10)$ & $0.18(34)$ \\
\hline Aquatic birds & $25 \%(27)$ & $6.33(90)$ & $2.33(9)$ & $0.33(8)$ & $0.25(2)$ & -- & -- & $0.72(17)$ & $6.33(12)$ & $2.09(78)$ \\
\hline
\end{tabular}

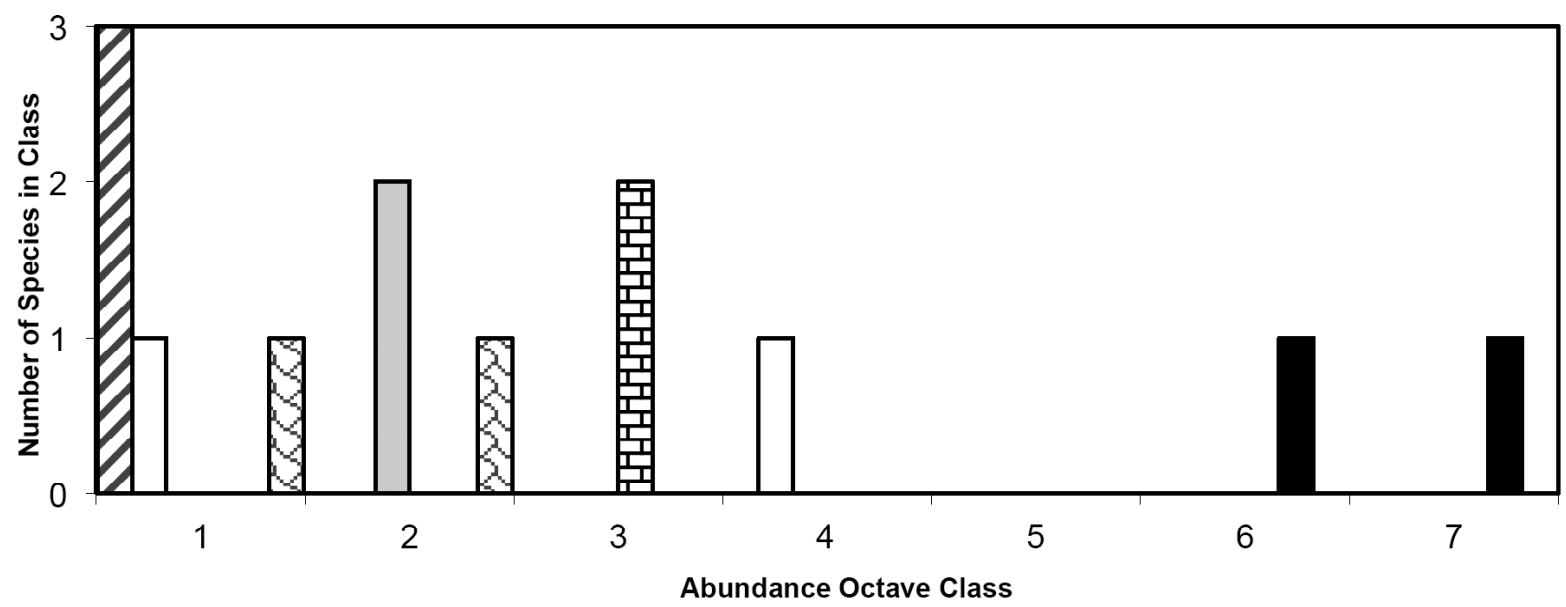

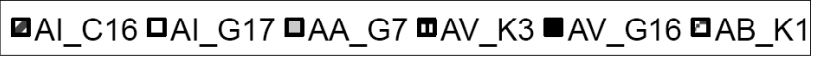

Fig. (5). Examples of incomplete local species assemblage abundance distributions. Each series label indicates the major taxon $(A I=A q u a t i c$ Invertebrates, $\mathrm{AA}=$ Aerial Insects, $\mathrm{AV}=\mathrm{Aquatic}$ Vertebrates, and $\mathrm{AB}=$ Aquatic Birds) and sample identification. AI_C16 and AB_K1 are truncated; the others are both truncated and missing representatives of abundance classes.

from the assemblage associated with the smallest, most remote habitats to the largest water bodies near the Main Pool or Clyde River (Large Pools). Thus, there were groups of Aquatic Birds that preferred or needed the largest open water areas available, while some species preferred medium size water bodies (e.g., Double-crested Cormorant and Great Blue Heron (Ardea herodias)) or Isolated Pools (e.g., Wood Duck (Aix sponsa) and Green Heron (Butorides virescens)).

\section{ABUNDANCE DISTRIBUTIONS AMONG SPECIES}

Sample assemblages fit both the geometric and log-series relative abundance distribution models, but the prevalence of each varied among major taxa and by spatial scales (Table 6). Many local assemblages (49\% - 90\%) fit the geometric distribution, but fewer $(25 \%-79 \%)$ fit the log-series distribution; many fit both. Local assemblages that fit neither model had missing abundance classes or truncated distributions (Fig. 5). In general, the proportion of assemblages that fit the log-series distribution increased as samples were grouped to represent larger spatial scales. Fit to the log-series distribution was good when sample assemblages were grouped by mean assemblage types (clusters) or major habitat type (Table 6). Fish in Isolated Pools, Aerial Insects in small habitats, and Aquatic 
Table 7. Mean Abundance $(N)(N o . / 100 ~ m 2)$, Species Richness $(S)$, and Diversity $\left(H^{\prime}\right)$, of Distinct Assemblages $(C l u s t e r s)$ for Each Major Taxonomic Group and Range and Overall Mean of those Indices for Sample Assemblages. The Number of Sample Assemblages Grouped into each Cluster is Denoted by n. The Anova F Statistic and Probability (P) of Significant Differences Among Assemblages are Shown. Summary of the Bonferroni Multiple Comparison Test Indicates which Means were Different from Others

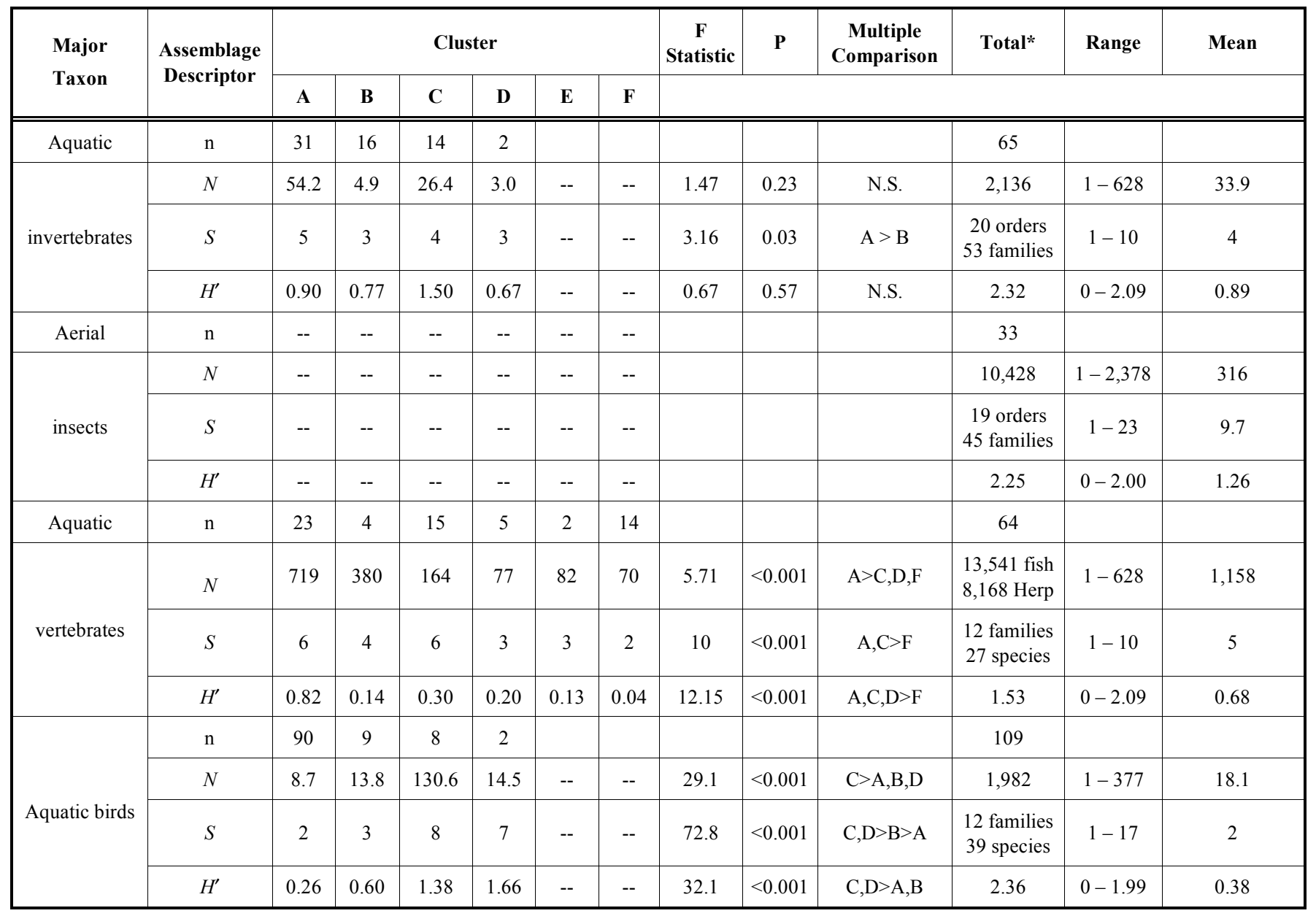

${ }^{*}$ Total $\mathrm{n}$ includes samples where no representative of the major taxon was present. Total ANOVA degrees of freedom are equal to Total $\mathrm{n}-1$; among groups degrees of freedom are equal to the one less than the number of groups being compared.

Invertebrates in large pools fit the logseries best $(\mathrm{K}<0.05)$. When all samples were pooled (i.e., metacommunity scale), all major taxa fit the log-series model well. Aquatic Vertebrates showed the clearest progression of relative abundance structure from most local assemblages fitting the geometric series to larger scale assemblages fitting the logseries distribution.

\section{MAJOR TAXA ASSEMBLAGE STRUCTURE AND HABITAT CONDITIONS}

Aerial Insects -- Although, no significant spatial or temporal structure was detected by cluster analysis, CCA identified trends associated with environmental gradients of depth, landscape slope, and water chemistry (Fig. 3b). The Isolated Pools were associated with $\mathrm{Pb}$ - and As-enrichment. Most organism optima clustered around the ordination origin, but Odonata and Limnophilidae were associated with Isolated Pools; few optima were closely associated with Large Pools samples.

Aquatic Invertebrates -- The Aquatic Invertebrate assemblage was uniform throughout the refuge ("General
Assemblage," cluster A), except in the Isolated Pools habitats (Fig. 6a). The CR Stage 1 restoration (cluster C) and reference (cluster B) assemblages were distinct from each other and from all other sites. A diverse assemblage (nearly as rich as the General Assemblage) occupied the Stage $1 \mathrm{CR}$ restoration site, dominated by oligochaetes and chironomids, with a large snail (Lymnaeidae) component. However, in Stage 2, the CR restoration assemblage (cluster D) had the lowest abundance and diversity; cladocerans, copepods (Copepoda), elmid beetles (Elmidae), and water mites (Hydrachnidae) became more abundant; and both gastropods and oligochaetes were absent. The Stage $1 \mathrm{CR}$ reference site assemblage (cluster B) was similar to that of the Stage 1 restoration site, but overall abundance was low. However, diversity and overall abundances among assemblages were not different (Table 7); mean taxon richness was greater in the general assemblage (Cluster A), than in the Stage $1 \mathrm{CR}$ reference assemblage (Cluster B), where fish were most abundant (see Aquatic Vertebrates below) (Table 7). There was considerable overlap of assemblages near the CCA ordination origin, but mean habitat conditions were significantly different among Aquatic 


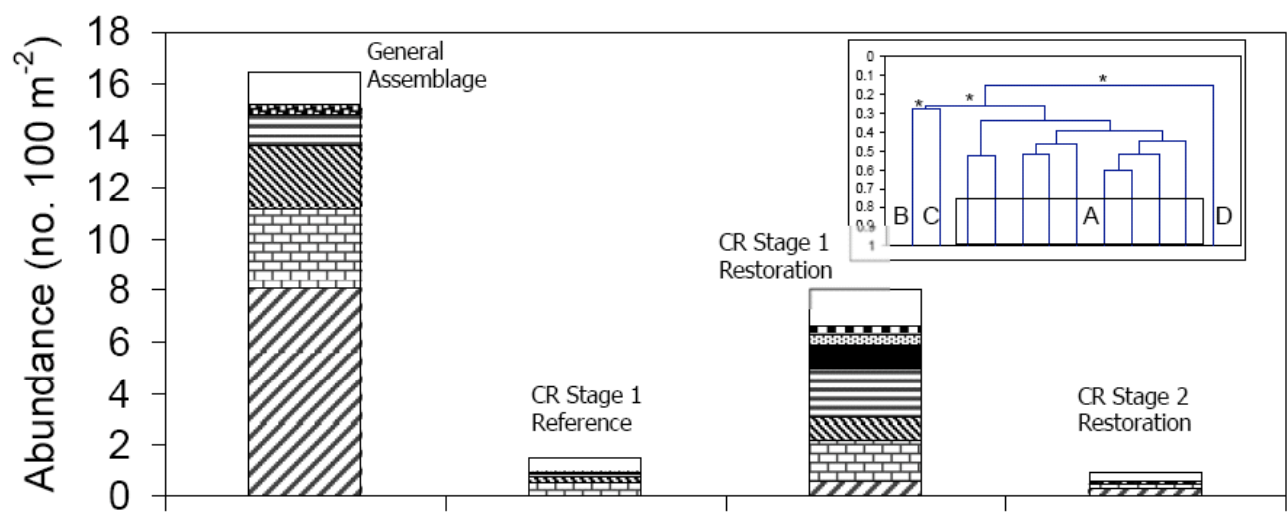

A $\quad B$

Cluster

\begin{tabular}{|c|c|c|c|c|}
\hline $\begin{array}{l}\text { Z Daphniidae } \\
\text { 国 Physidae }\end{array}$ & $\begin{array}{l}\text { (5 Chironomidae } \\
\text { 国 Copepoda }\end{array}$ & $\begin{array}{l}\mathbb{N} \text { Gastropoda } \\
\text { Dytiscidae }\end{array}$ & $\begin{array}{l}\text { ⿴囗⿱一一 O Oligochaeta } \\
\square \text { other }\end{array}$ & - Lymnaeidae \\
\hline
\end{tabular}
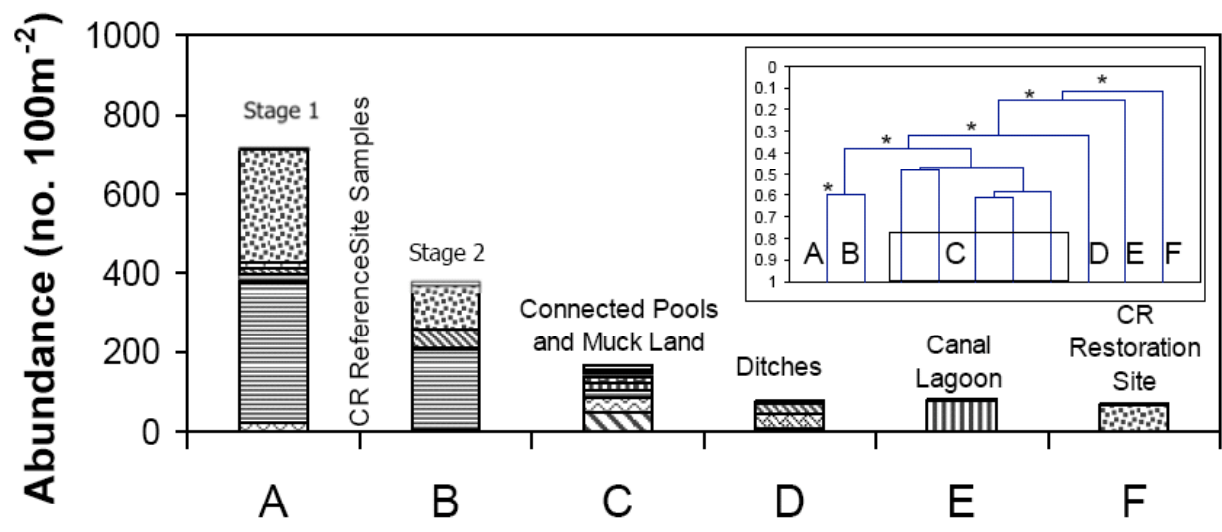

\section{Cluster}

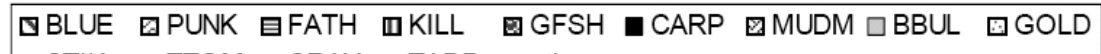
\$STIK $\square$ TTOM GCRAY GTADP $\square$ other

6b

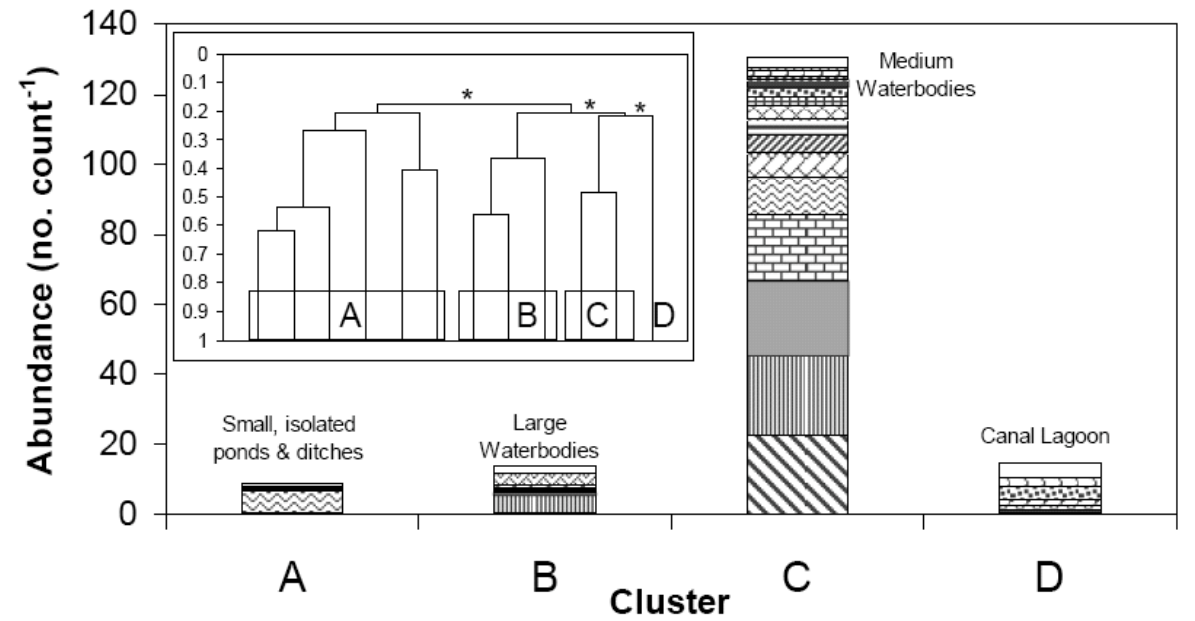

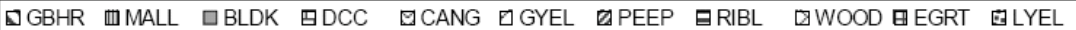
$\square$ BLTE $\triangle$ GREB $\square$ KILL $\square$ HOOD * AMWG $\square$ other

Fig. (6a). Distinct Aquatic Invertebrate assemblages. Stacked bar chart shows abundance and species composition of each distinct assemblage (designated by upper case letter). Cluster A represents the General Assemblage, Cluster B represents CR reference site assemblage, Cluster C represents Stage $1 \mathrm{CR}$ restoration site assemblage, and Cluster D represents Stage 2 CR restoration site assemblage. Inset dendrogram shows 
each significantly distinct group of samples, marked by a letter, and each linkage joining two significantly distinct groups, indicated with an asterisk*. Bray-Curtis similarity is shown along the ordinate. 6b) Distinct Aquatic Vertebrate assemblages. Stacked bar chart and inset dendrogram as described above. Cluster A represents the Stage 1 CR reference site assemblage, Cluster B represents Stage 2 CR reference site assemblage, Cluster $\mathrm{C}$ represents the large connected pools assemblage, Cluster D represents the ditch habitat assemblage, Cluster E represents the canal lagoon assemblage, and Cluster F represents the Stage 2 CR restoration site assemblage. Cluster designations and species codes match those of Fig. (3), with the addition of CRAY = crayfish spp., GFSH = goldfish, and GOLD = golden shiner. 6c) Distinct Aquatic Bird assemblages. Stacked bar chart and inset dendrogram as described above. Cluster A represents the small, isolated and ditch habitats assemblage; Cluster B represents the assemblage of large water bodies; Cluster C represents the assemblage of medium water bodies; and Cluster D represents the Canal Lagoon assemblage. Species codes are defined in Fig. (3), with the addition of EGRT = Great Egret, GRHR = Green Heron, PEEP = small sandpiper spp., RIBL = Ring-billed Gull, and WOOD = Wood Duck.

Invertebrate assemblages. Fish Abundance, OM, and Water Temperature had the strongest influences, but three chemical elements (Se, B, and Mo) were also significant (Fig. 3a). Stage 1 samples were collected during a time of drought and the Stage $1 \mathrm{CR}$ reference site was chemically enriched (above dataset mean), with elevated levels of As $(\bar{\chi}=0.022$ ppm), B $(\bar{\chi}=0.968 \mathrm{ppm}), \mathrm{Cr}(\bar{\chi}=0.008 \mathrm{ppm})$, Mo $(\bar{\chi}=$ $15.001 \mathrm{ppm})$, and $\mathrm{Se}(\bar{\chi}=0.008 \mathrm{ppm})(\mathrm{P}<0.05)$. Phosphorus values were the highest observed $(\bar{\chi}=3.409$ ppm) and Fish Abundance was much greater than in any of the other habitats $(\mathrm{P}<0.01)$ (Appendix 1). Precipitation was high during Stage 2 and CR restoration site conditions were chemically dilute (below dataset mean).

Aquatic Vertebrates -- Six distinct species assemblages were identified and differed in abundance, richness, and diversity, as well as composition (Table 7, Fig. 6b). Stage 1 (cluster A) and Stage 2 (cluster B) CR reference site assemblages were distinct and dominated by fathead minnow and tadpoles, with an increased abundance of brook stickleback (Culaea inconstans) in the Stage 2 samples. Abundance of Stage $1 \mathrm{CR}$ Reference site vertebrates (cluster A) was greater than that of other assemblages and was also the richest and most diverse (Table 7). A unique assemblage occupied Ditches habitat (cluster D) and was characterized by low abundance and dominance by brook stickleback and central mudminnow (Umbra limi), but was significantly more diverse than that of the $\mathrm{CR}$ restoration site (Cluster F) where fish were absent. The assemblage occupying Large Pools (cluster C) was relatively rich (six species / sample) and diverse (0.3), and characterized by abundances similar to other connected or nearby habitats (clusters D and E); bluegill (Lepomis macrochirus), pumpkinseed (Lepomis gibbosus), and fathead minnow dominated. A small assemblage dominated by banded killifish (Fundulus diaphanus), but also including species associated with deep, warm water (e.g., emerald shiner (Notropis atherinoides) and smallmouth bass (Micropterus dolomieu)) was unique to the Canal Lagoon (Cluster E); that habitat occupied a site directly connected to the Seneca River (Fig. 1).

Environmental conditions differed among Aquatic Vertebrates clusters (Appendix 1). Assemblages generally separated along Mn, Piscivorous Birds, OM, and conductivity gradients (Fig. 3c) and only the CR assemblages overlapped the Large Pools assemblage space in the CCA ordination. Nearly all species optima fell within the Large Pools space, but the toad tadpole (Bufo spp.) optimum was unique to the Ditches assemblage, while tadpole madtom (Noturus gyrinus) and fathead minnow optima were centered within the CR reference site space. Most of the habitats, including the Large Pools and connected sites (Cluster C), had moderate abiotic conditions, but Piscivorous Bird abundance was the highest. Isolated Pools (CR sites, cluster A, B, and F) had fine sediments and chemically enriched waters, but with low $\mathrm{Na}$ and few Piscivorous Birds; Aquatic Invertebrate abundance was low in the CR reference site. The Ditches habitat sites (cluster D) were shallow, in areas of low landscape slope, and dissolved oxygen and $\mathrm{pH}$ were very low, but $\mathrm{OM}$ and $\mathrm{Si}$ were the highest observed; Aquatic Invertebrate abundance was moderate, but there were few Piscivorous Birds. The Canal Lagoon (cluster E) had the highest values of Conductivity and $\mathrm{Na}$ and sediment was coarse; Piscivorous Bird abundance was low and Aquatic Invertebrate abundance moderate in this small habitat.

Aquatic Birds -- The four Aquatic Bird species assemblages were associated with different habitat conditions (Appendix 1) and overlapped considerable near the ordination origin; the best separation occurred along water body size, depth, and water chemistry gradients (Fig. 3d and Fig. 6c). Birds did not distinguish between ditch habitat and small isolated pools (Cluster A) and most samples (90) came from those habitats (Table 7). Twentythree species composed this Canada Goose-dominated assemblage, but mean abundance was low ( 8.7 birds/count) and mean species richness (2/ sample) and diversity $(0.26)$ the lowest observed. Assemblages found in large (Cluster B) and medium (Cluster $\mathrm{C}$ ) open water pools were distinct, with the large pool assemblage having relatively low abundance (13.8 birds/count), richness (3/sample), and diversity (0.60), and consisting of mostly dabbling ducks. Medium size habitats adjacent to the Clyde River (Stage 2, post-flood, muckland samples and Mays Landing) supported a rich (8/ sample) and diverse (1.38) assemblage with the most Aquatic Birds (131) (Table 7). Bird abundance in this assemblage was nine to fifteen times greater, on average (130.6 birds/count), than that of the other assemblages. Great Blue Heron, Mallard, American Black Duck, and Doublecrested Cormorant were the most common of the 27 species observed. The canal lagoon (cluster D) supported a unique assemblage characterized by moderate species richness (7/ sample) and the highest diversity (1.66) but, was represented by only two samples and among the eleven species observed, Greater Yellowlegs (Tringa melanoleuca), Lesser Yellowlegs (Tringa flavipes), and Killdeer (Charadrius vociferus) were most common. Large habitats (Cluster B) had higher conductivity $(\bar{\chi}=1127 \mu \mathrm{s} / \mathrm{cm}), \mathrm{Ca}(\bar{\chi}=114.543$ ppm), $\operatorname{Mg}(\bar{\chi}=22.736 \mathrm{ppm}), \mathrm{S}(\bar{\chi}=104.520 \mathrm{ppm})$, and $\mathrm{Si}(\bar{\chi}$ $=2.211 \mathrm{ppm})$ values than most habitats associated with other bird assemblages, while the small habitats (Cluster A) were on average deeper, had elevated $\mathrm{Se}(\bar{\chi}=0.007 \mathrm{ppm})$ levels, and contained an abundance of fish. The medium size habitats (Cluster C) had low levels of Si $(\bar{\chi}=0.382 \mathrm{ppm})$ and Se $(\bar{\chi}<0.001 \mathrm{ppm})$ and moderate Fish Abundance. Most 
species optima were scattered around the origin within the space occupied by the medium water body assemblage, but several were associated with large (e.g., American Coot (Fulica americana), American Wigeon (Anas americana), Least Sandpiper (Calidris minutilla)) or small water bodies (e.g., Gadwall (Anas strepera), Black Duck (Anas rubripes), Forsters Tern (Sterna forsteri), Solitary Sandpiper (Tringa solitaria), Pied-billed Grebe (Podilymbus podiceps), and Horned Grebe (Podicpes auritus)). Seven species optima were unique to the broad area occupied by Ditches and Isolated Pools habitat (Belted Kingfisher) (Megaceryle alcyon), Blue-winged Teal (Anas discors), Canada Goose, Hooded Merganser (Lophodytes cucullatus), Killdeer, Mallard, and Swamp Sparrow). These species are not necessarily restricted to that habitat, but are widespread and may be more frequently observed in small habitats.

\section{DISCUSSION}

This study quantifies community structure and reveals some of the dynamics of this wetland ecosystem, which functions as a metacommunity with separate habitat patches of three general types (Large Pools, Ditch-like Habitats, and Isolated Pools) having various levels of connectivity (Leibold et al. 2004, Falke and Fausch 2010). How the organisms structure themselves within this (or any natural) ecosystem and how that structure is maintained are basic ecological questions and several models provide context for interpretation of the observations (see Appendix 2 for a brief summary). The results of this study indicate that each class of organism is generally structured into distinct assemblages whose spatial arrangement and associated environmental conditions suggest behavior most like the Mass Effect paradigm or Species Sorting paradigm (Whittker 1972, Leibold et al. 2004) or a combination of both metacom-munity types. The emphasis on one metacommunity type or other varied by class. Scale is also clearly important and I discuss the findings below in order of decreasing spatial and temporal scale. This allows us to see the broadest ecological boundaries imposed on the ecosystem and step down through the scales to factors affecting any particular habitat within the system.

\section{LARGE SCALE ECOLOGICAL BOUNDARIES}

Historic, large-scale events determine the pool of species available in a particular region (Matthews 1998). Glaciers eliminated fish from nearly all of New York State and much of the Northeast US and were responsible for many of the conduits of fish recolonization as they receded (Smith 1985). Fish re-invaded New York waters from several different glacial refuge sources (e.g., Mississippi and Atlantic Refuges) (Schaffner and Oglesby 1978, Muller and Prest 1985, Mandrak and Crossman 1992). The MWC is located at the crossroads for several of these pathways. The area is also host to a large pool of resident and migratory birds. Similarly, most aquatic insects have aerial dispersal stages (Merritt and Cummins 1984) and many other aquatic invertebrates are carried by birds (Schlichting 1960, Proctor and Malone 1965), thus disperse widely, quickly colonizing new areas (Bogan and Boersma 2012). These events and conditions, as well as human activities (e.g., fish stocking), result in the pool of species we find present in the region today.
Primary productivity sets overall ecological potential for any ecosystem and also largely determines potential complexity of the food web (Fretwell 1987, Jenkins et al. 1992, Power et al. 1996, Menge 2000). Results from an earlier study showed that aquatic productivity in at least some of the study habitats (CR) is relatively high (for temperate freshwater systems) and is enhanced by supplementation from surrounding terrestrial sources (McKenna 2003a). Thus, abundances of primary consumers in the MWC are potentially high and food webs can be complex (four or more trophic levels). Within these boundaries, the aquatic community is structured in space and time by a combination of local, landscape, and insular features; biotic interactions; and variability on multiple scales.

\section{MODERATE SCALE INFLUENCES}

Assemblage richness and structure -- The relationship between species richness and abundance is a basic descriptor of living community conditions and can be represented in several ways (Fisher et al. 1943, Kobayashi and Kimura 1994, Ricklefs and Miller 2000, Hubbell 2001, He and Legendre 2002). Richness of sample assemblages (major taxa combined) was as high as 30 , but $90 \%$ of assemblages were composed of fewer than 10 taxa, indicating that communities were relatively simple at any given site or point in time; species-specific resolution of invertebrates would increase this number. Cluster analysis considers both species composition and relative abundance and detected significant spatial (and in some cases, temporal) structure among assemblages for each major taxon, except Aerial Insects. Spatial structure did not match exactly among major taxa but, similarities among these structures revealed three major habitat types: 1) relatively large, well-connected pools, 2) small ditch-like habitats connected to the large pool network, and 3) small, isolated pools (i.e., CR sites). Dissimilarities among assemblages help identify the role of ecological strategies and life history adaptations used in dealing with local biogeographic arrangements of habitats and variability within this wetland system. For example, the fish assemblage of large, well-connected pools was the most diverse and included species like bluegill and pumpkinseed that rely on relatively stable conditions to maintain their populations. Whereas, the ditch habitat assemblage consisted largely of pioneer species like brook stickleback and central mudminnow. The isolated pool of the CR reference site was dominated by fathead minnow, a species that may not be as good a pioneer as brook stickleback but can be quite abundant if established in a system without large piscivores (Smith 1985, Robinson and Tonn 1989).

Habitat size, connectedness, and spatial arrangement -The general nature of the species assemblages and their spatial arrangement within MNWR indicates that habitat configuration and insular effects, such as habitat patch size and connectivity, affect the character of aquatic species assemblages in the study area. As designed, the SCI index identified the smallest and most isolated habitats (Isolated Pools and Ditches) as the most difficult to recolonize (SCI < 3 ), while habitats associated with the large pools were the easiest to recolonize. Spatial assemblage structure generally agreed with this configuration. Only the most isolated sites 
contained distinctly different Aquatic Invertebrate assemblages (low abundance and richness) from those occupying other parts of the study area. Similarly, fish assemblages in small remote habitats were less diverse than those in larger habitats near the center of the refuge. The most diverse and higher abundance Aquatic Bird assemblages were generally found in large "source" habitats rather than the smaller more difficult to reach ditch and isolated habitats (Howeth and Leibold 2010b), but aquatic conduits were irrelevant and birds did not distinguish between these small habitats. While spatial factors affected all organism classes, habitat conditions also explained a large component of assemblage structure.

\section{FINE-SCALE FACTORS}

Evidence for control by habitat condition and disturbance-Superimposed on system productivity and spatial orientation are the dynamic effects of disturbance and recovery. Biotic communities responded to several abiotic factors, and linkages to other trophic levels (e.g., OM and Piscivorous Fish), indicating habitat limitations for various species (Figs. 3 a-c). In addition, diversity-SCI relationships support theories emphasizing dispersal ability combined with island biogeographic processes. Present biotic communities are the end result of disturbance-caused local population reduction or extinctions, re-colonization, and competition and predation events that have occurred in recent generations. Small wetland habitats are likely to experience more frequent and more intense thermal and desiccation stresses than large habitats, as well as disproportionately large changes in habitat volume. Re-colonization rate of disturbed areas will be limited by their degree of isolation (as well as their size) and the number of local refuges (also size dependent) capable of supporting remnant populations throughout a disturbance event (MacArthur and Wilson 1967, Hubbell 2001, Howeth and Leibold 2010a, Howeth and Leibold 2010b). Connectivity among small and large habitats may moderate the effects of disturbance (Shmida and Wilson 1985). Community structure typically varied by major habitat type, with Ditches habitat having simple, species depauperate assemblages, including few fish and birds (Figs. $4 \&$ 6). Invertebrate components of these communities were similar to, but subsets of the assemblages of large habitats (Ruhi et al. 2013). The largest pools have the largest habitat volume and would be the last habitats substantially affected by disturbance and likely to contain the most refuges from disturbance. In the MNWR, assemblages of the relatively large connected pools were diverse and quite similar. Smaller habitats were connected to these by canals and culverts. This provided a source-sink arrangement of habitats, allowing both rapid recolonization of disturbed areas via a variety of conduits and easy access to refuges for inhabitants of smaller connected habitats when conditions deteriorate.

Differences in behaviors and life histories (particularly dispersal) among major taxa help explain differences in taxa abundance distributions. Local assemblages were typically small and dominated by a few common taxa. The fit of local assemblages (alpha-diversity) to the geometric distribution and larger-scale communities (beta-diversity) to the logseries model is expected by Neutral Model theory (Hubbell 2001) and suggests that community organization was determined by relatively few factors (Hall et al. 2004) (Tables 3, 6, \& 7). However, several assemblages fit neither the geometric nor the log-series distributions, largely because of missing abundance classes, a pattern indicative of disturbed habitat; such habitats are not species saturated, a basic assumption of most community models (Hubbell 2001). We would expect many local MNWR assemblages from small habitats to be susceptible to disturbance and often in a state of recovery. The recovery rate depends upon immigration and reproductive (for invertebrates) rates (Howeth and Leibold 2010a, Howeth and Leibold 2010b). Different dispersal rates and mechanisms among the major taxa are reflected by the degree to which taxon abundances fit the log-series distribution. Highly mobile organisms, (i.e., those that fly, Aerial Insects and Aquatic Birds), can by-pass the aquatic conduit system and disperse readily. Because Aerial Insects are prolific and may disperse by either water courses or by flight, they are capable of quickly colonizing any aquatic habitat and displayed no spatial structure (simply random subsets of the Aerial Insect metacommunity) or relationship to SCI, indicating no preference for habitat size or location (Ruhi et al. 2013). Aquatic Birds can also repopulate habitat quickly and distance (on the scale of this study) is not a limitation. However, they were highly structured, preferring large habitats, with distinctly different species assemblages in small habitats. Advanced behaviors allow birds to aggregate in good foraging areas by queuing on behaviors of other birds (Ward and Zahavi 1973, Ricklefs and Miller 2000). Thus, the high mobility of Aerial Insect and Aquatic Bird assemblages allows them to recover quickly by rapidly recolonizing available habitat. Aquatic Invertebrates are also prolific but may disperse overland by flight only during their brief adult stage or when carried by mobile vertebrates (e.g., Aquatic Birds). Dispersal may also occur via water course for these animals. Their dispersal may be relatively slow, but they may also be better able to retain local populations in habitat that is susceptible to common environmental stresses (e.g., thermal or desiccation) than are fish, because they may survive in smaller habitat volumes and may be physiologically more resistant to such disturbances (Menge and Sutherland 1987, Pennak 1989, Menge 2000). Thus, they may also be able to re-colonize disturbed areas more quickly than can fish. This would contribute to the weaker spatial structure of Aquatic Invertebrates than that for fish. Fish are not as prolific as aquatic insects and are generally restricted to water courses for dispersal. Fish dispersed within MNWR only fast enough to maintain poor assemblages in small distant habitats but richer assemblages in larger well connected habitats, resulting in relatively well-developed spatial assemblage structure with distinct assemblages (Jude and Pappas 1992, Mitsch and Gosselink 2006). However, Isolated Pool habitats did not fit the expected pattern of decreasing fish assemblage richness with increasing isolation. Despite its isolation, the $\mathrm{CR}$ reference site assemblage was relatively diverse with the highest fish abundance. This small site was surrounded by woods and fed by groundwater from the local watershed, which provided relatively stable conditions and resistance to some short-term disturbances; also, no large piscivores were present. Rare recolonization events coupled with a relatively stable environment and rich resources allowed the diverse assemblage to develop. The change in the fish assemblage 
(reduced dominance by fathead minnow) near the end of the drought (late in Stage 2) might be a response to desiccation (and reduced volume) disturbance of that habitat (Fig. 6b).

Evidence of biotic control--Biological control of populations and trophic level composition can be affected from bottom-up, top-down, or both (Polis and Winemiller 1996, Menge 2000, Ricklefs and Miller 2000). Occurrence of rich and abundant invertebrate assemblages where fish were absent (and vice versa), suggests predatory effects, but is not sufficient to establish trophic cascade in these systems (Fretwell 1987, Kitchell and Carpenter 1993, Howeth and Leibold 2008, Howeth and Leibold 2010a) (Fig. 6a). Significant associations of biotic gradients with higher and lower trophic level biotic influences (Fig. 3a \& 3c) suggest both top-down and bottom-up regulation in the case of Aquatic Invertebrates and Aquatic Vertebrates. Aquatic Invertebrates separated into assemblages found in habitats with different abundances of fish (Fig. 6a \& $\mathbf{6 b}$ ) and Total Fish Abundance was important (Fig. 3a), indicating a topdown influence; OM was also important, suggesting possible bottom-up effects. Aquatic Vertebrates responded to both bottom-up (Total Invertebrate Abundance and $\mathrm{OM}$ ) and topdown (Piscivorous Bird Abundance) influences (Fig. 3c). Thus, interclass relationships affect the Species Sorting dynamics of the metacommunity. No biological or habitat productivity control was evident on the Aerial Insects (Fig. 3b). Aquatic Birds responded to Total Fish Abundance, suggesting possible bottom-up regulation (Fig. 3d). However, it seems unlikely that bird populations were truly limited by fish availability within the study area. Most Aquatic Birds are long-lived, highly migratory, and do not complete their entire life cycle within the study area. The association with fish (or invertebrate) abundance may simply be an indication of their great mobility and use of advanced behaviors to efficiently target abundant food sources and optimize foraging (Ward and Zahavi 1973, Welty 1973, Ricklefs and Miller 2000).

\section{COMMUNITY COMPLEXITY AND DIVERSITY}

While the results support some elements of each of the four metacommunity paradigms, a combination of the two spatially explicit models, with an emphasis on Species Sorting best represents the MNWR metacommunity. The clear heterogeneity of habitat patches precludes the Patch Dynamics metacommunity type. Neutral models [e.g., Hubbell 2001) also assume uniform habitat conditions and treat all species and individuals as equivalent. This paradigm explains many aspects of natural communities, but would not capture the dynamics of the multispecies aquatic assemblages of MNWR well.

Aerial Insects displayed only weak habitat controls (Fig. 3b) and were not influenced by spatial factors (Table 4). Most species optima were associated with Ditch-like habitat, but there was no spatial structure to this assemblage. This prolific and highly mobile major taxon appears to be broadcast across the landscape and local assemblages, similar to the area-wide community, occurred in all aquatic habitats. A weak Species Sorting effect may have resulted in enhanced abundances within Ditches habitats.

The better defined Aquatic Invertebrate and Aquatic Vertebrate assemblage structures indicated that spatial factors, as well as environmental conditions, contributed to metacommunity structure and dynamics for these classes of organisms. Aquatic Invertebrate assemblages were structured in space and species richness responded to SCI, but only weakly $\left(\mathrm{R}^{2}=0.07\right)$ (Table 4). The similarity among connected habitats indicates that Aquatic Invertebrates may recolonize local habitat within the network quickly, and the distinct assemblages within Isolated Pools shows that connectivity is important. However, the declining richness with smaller SCI suggests that fewer species niches may be accommodated in smaller habitats. This and the significant associations with environmental conditions (including trophic links) (Fig. 3a) suggest a Species Sorting metacommunity type rather than Mass Effect.

Aquatic Vertebrate and Aquatic Bird assemblages were highly structured in space. Distinct Aquatic Vertebrates assemblages aligned well with major habitat types and Aquatic Vertebrates diversity increased with habitat size and connectivity (Table 4) but, SCI explained only $14 \%$ of variation in Aquatic Vertebrates diversity. Ditches habitats are smaller and less diverse than Large Pool habitats and also more susceptible to desiccation and thermal extremes in summer and freezing in winter. Higher trophic levels are generally more strongly affected by environmental stresses (Connell 1978, Menge and Sutherland 1976, Lubchenco and Gaines 1981, Menge 1983) and fish were probably more thoroughly excluded from these habitats during extreme conditions than invertebrates. Fish can quickly move into these connected habitats when conditions are favorable and a Mass Effect type dynamic could be maintaining those assemblages. However, environmental factors (including trophic links) had a strong influence (Fig. 3c) and the number of species capable of existing in this habitat is limited. The dominant species (brook stickleback and central mudminnow) of the small habitats were good colonizers, tolerant of stress and variable habitat conditions (Smith 1985). Thus, Species Sorting is probably responsible for most of the fish community dynamics. Controlled experiments are needed to determine if species richness is enhanced in these marginal habitats by Mass Effect (Shmida and Wilson 1985) or if there are frequent local extinctions of fish.

Bird assemblage spatial structure was clear (Fig. 6c), but did not match the major habitat types and relationships with SCI explained $<39 \%$ of variability. The vast majority of bird diversity and abundance was found in large water bodies (Table 4) and environmental factors were important (Fig. 3d). Mass Effect could be supplying birds to the small habitats, but the few species found there (e.g., Green Heron, Wood Duck, and Least Bittern (Ixobrychus exilis) were distinct from the Large Pools assemblages and prefer smaller aquatic habitat. From their great mobility we might expect that spatial factors would not be most important to Aquatic Bird metacommunity dynamics. Advanced behaviors and active selection for preferred habitat conditions conform to Species Sorting and may override Mass Effect dynamics. Analysis of bird assemblages at a larger scale may reveal different dynamics.

\section{TEMPORAL CHANGES}

Spatial community structure was well-documented by available samples. However, temporal changes could only be 
detected at a few locations. Initial flooding of the CR restoration site (at the beginning of Stage 1) made a large store of terrestrially produced organic matter available to both decomposers and grazers (McKenna 2003a). The changes in invertebrate assemblages from Stage 1 to Stage 2 are expected as the assemblage matures (Ruhi et al. 2013) and that non-renewable resource declines. The reduction in diversity may be an indication that sufficient time had passed for superior competitors to arrive and exclude some groups. At the same time, the region was experiencing drought conditions that may have affected that aquatic community. Those effects are more evident at the CR reference site, which continued to shrink in volume throughout the Stage 1 study (McKenna 2003a). Fathead minnow and tadpoles were strongly dominant members of the aquatic assemblage at the beginning of the time period. However, by the end of Stage 2 , overall abundances had decreased, and brook stickleback (a pioneer species) became a more prominent component of the assemblage; some species were extirpated. It is unclear whether release from competition allowed the pioneer species to expand, or if another mechanism caused the assemblage change.

\section{CONCLUSIONS}

The Montezuma Wetland Complex species assemblages clearly vary in space and time and differ by major taxon. The MNWR aquatic ecosystem is best understood as a relatively productive, metacommunity, populated by members of a post-glacial species pool. The adaptations of the inhabitants allow them to interact and respond to environmental disturbance and biotic changes, such that distinct assemblages are maintained within three major habitat types. However, each class of aquatic organisms deals with the fragmented and partially connected network of habitats differently. Aerial Insects show little or no metacommunity dynamics, occupying all aquatic habitats regardless of connectivity. Aquatic Invertebrates and fish showed evidence of metacommunity dynamics driven by both Mass Effect and Species Sorting effects, with an emphasis on the latter. Aquatic Birds appear to modify basic Species Sorting metacommunity dynamics with advanced foraging and social behaviors. The multi-taxon and trophic level integration approach taken here helps to identify broad community conditions and couplings across food web components, but has rarely been applied (Beisner et al. 2006, Presley et al. 2012); this is the first wetland application.

This investigation supports management goals within the MWC by providing an assessment of the spatial distribution of aquatic biodiversity and a better understanding of wetland community structure and dynamics. The observed correlations between habitat conditions and distinct assemblages indicate the driving influence of environmental factors, spatial habitat configuration and connectivity, and temporal dynamics in creating the biotic landscape. Local extinction is likely an integral part of this fragmented system, depending on environmental variability. Active management of wetland habitat within the MWC is typically affected by opening and closing connective conduits (i.e., altering water supply) at various times, thus applying environmental stresses and changing habitat volume and connectivity. This can provide the means and opportunities for organisms to escape disturbance and recolonize habitat and can change community structure within the MWC (Hubbell 2001). Additional work on hydrology, broader watershed conditions, organism life histories (especially of Aquatic Invertebrates), and controlled experiments on organism demographics and movements would help clarify the processes of community maintenance in this and other wetlands.

\section{CONFLICT OF INTEREST}

The authors confirm that this article content has no conflicts of interest.

\section{ACKNOWLEDGEMENTS}

Assistance from T. Jasikoff, T. Gingrich, and other US Fish and Wildlife Service staff at the Montezuma National Wildlife Refuge was crucial to the success of this work. I am grateful to C. Ewell-Hodkin, P. Randall, and all of the volunteers who assisted with field collections and laboratory work for this study. I am indebted to R. Butryn, D. McDonald, and K. Douglass for their assistance with data analysis and mapping. My thanks go to D. Dittman and other reviewers that have helped improve this manuscript. This is Contribution \#1748 of the U.S. Geological Survey Great Lakes Science Center.

\section{APPENDIX}

APPENDIX 1. Anova Results Summary For Differences In Influential Abiotic Factors Of Habitats Associated With Distinct Assemblages Of Each Major Taxon

\begin{tabular}{|c|c|c|c|c|}
\hline Major Taxon & Variable & F & P & Comparisons \\
\hline \hline Aquatic & OM & 0.37 & 0.776 & N.S \\
\hline Birds & Aquatic Invertebrates & 31.15 & $<0.001$ & C $>$ A,B,D \\
\hline$($ d.f. $=3)$ & Area & 14.65 & $<0.001$ & B $>$ A,C,D \\
\hline & As & 2.92 & 0.038 & N.S. \\
\hline & Bank Slope & 9.65 & $<0.001$ & A $>\mathrm{B}, \mathrm{D}$ \\
\hline & Ca & 5.13 & 0.003 & $\mathrm{~B}>\mathrm{A}, \mathrm{C}$ \\
\hline & Conductivity & 18.93 & $<0.001$ & $\mathrm{~B}>\mathrm{A}, \mathrm{C} \mathrm{D}>\mathrm{A}, \mathrm{B}, \mathrm{C}$ \\
\hline
\end{tabular}


Appendix Table 1. Contd...

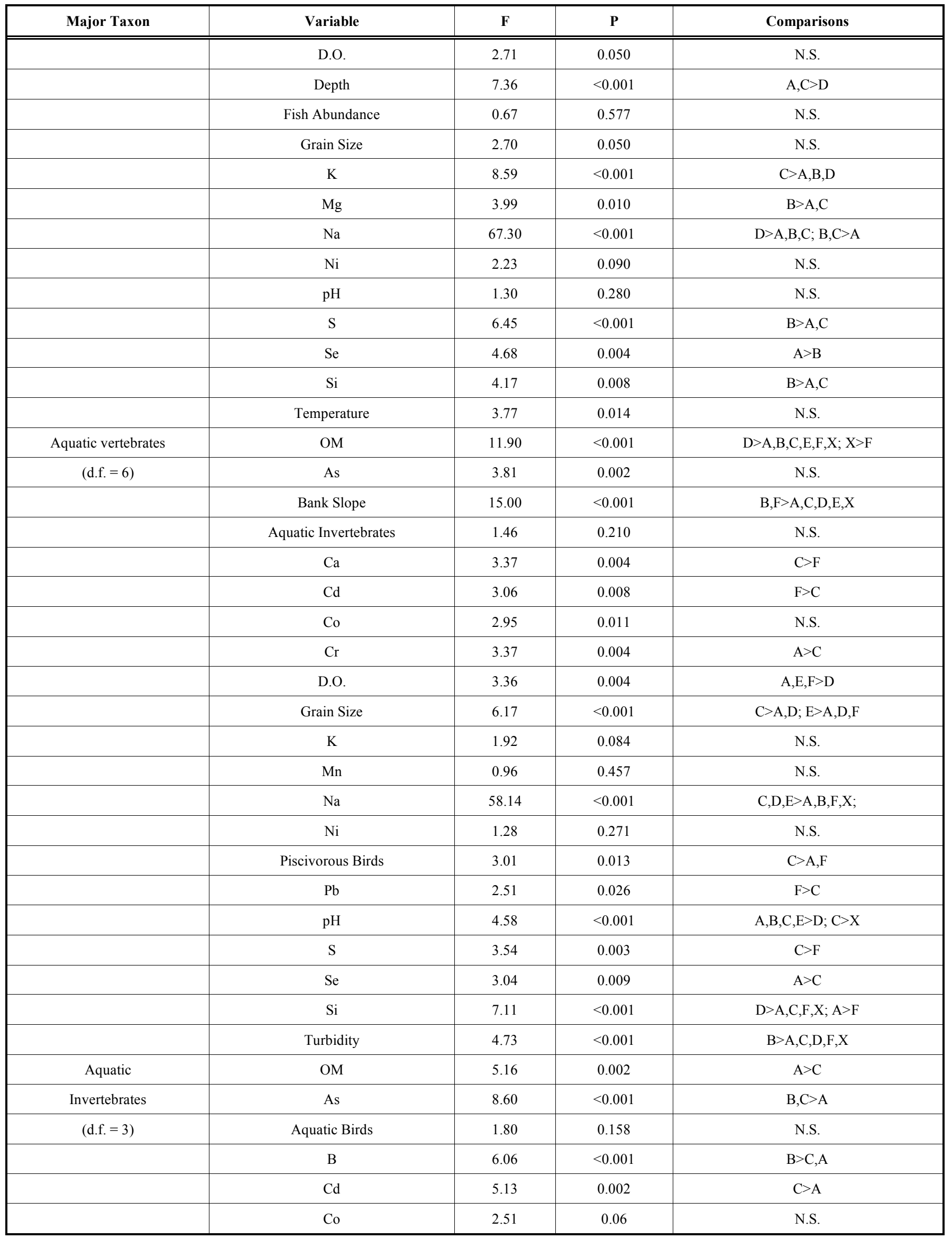


Appendix Table 1. Contd...

\begin{tabular}{|c|c|c|c|c|}
\hline Major Taxon & Variable & F & P & Comparisons \\
\hline \hline & $\mathrm{Cr}$ & 9.78 & $<0.001$ & $\mathrm{~B}, \mathrm{C}>\mathrm{A}$ \\
\hline & Fish Abundance & 9.41 & $<0.001$ & $\mathrm{~B}>\mathrm{A}, \mathrm{C}$ \\
\hline & Grain Size & 3.81 & 0.012 & $\mathrm{~A}, \mathrm{C}>\mathrm{B}$ \\
\hline & $\mathrm{Mo}$ & 4.64 & 0.004 & $\mathrm{~A}>\mathrm{A}, \mathrm{C}$ \\
\hline $\mathrm{Na}$ & 14.23 & $<0.001$ & $\mathrm{C}>\mathrm{A}$ \\
\hline $\mathrm{Pb}$ & 7.52 & $<0.001$ & $\mathrm{~A}>\mathrm{C}$ \\
\hline & $\mathrm{S}$ & 5.16 & 0.002 & $\mathrm{~B}, \mathrm{C}>\mathrm{A}$ \\
\hline
\end{tabular}

\section{APPENDIX 2. COMMUNITY THEORY CONTEXT}

The complex spatial and temporal organization and dynamics of wetlands are best interpreted within the context of ecological theory. The available body of theory helps to establish the ecological boundaries of a system and define the mechanisms of change within the system. This is not a formal attempt to unify theory (sensu Hubbell 2001, Scheiner and Willig 2005), but I here summarize general theories of processes and mechanisms for community structuring to provide a spatial and temporal framework for discussion of wetland community dynamics.

Ecosystem carrying capacity is the result of ecological productivity and ultimately determines the abundance of biological organisms and the complexity of their relationships (Pearl and Reed 1920, Lotka 1925, Elton 1927, Lindeman 1942, Hairston et al. 1960, Fretwell 1987, Menge and Sutherland 1987, Menge 2000). If productivity is sufficiently large, higher trophic levels and a progressively more complex food web develop (Oksanen et al. 1981, Fretwell 1987, Jenkins et al. 1992, Power et al. 1996, Menge 2000). For example, Svärdson's (1976) comparison of oligotrophic and eutrophic lakes showed that the more productive lakes supported more trophic levels than did the less productive lakes. As a higher trophic level develops and organisms of that level become more abundant and the assemblage more complex, a threshold can be reached at which that trophic level has a regulatory effect on the next lower trophic level (Menge 2000). This can cause a "trophic cascade" that results in development and maintenance of different forms of organisms at each lower trophic level (Kitchell and Carpenter 1993, Zimmer et al. 2000). Physical and physiological disturbance can limit this entire community development process (Connell 1978, Menge and Sutherland 1987); that, in turn, is moderated by recruitment processes and adaptations of species within the available species pool (Connell 1985, Roughgarden et al. 1985, Menge and Sutherland 1987). Connell's (1978) Intermediate Disturbance Hypothesis, and Menge and Sutherland's (Menge and Sutherland 1987, Menge 2000) subsequent modifications to incorporate effects of recruitment, have some of the broadest application to ecological communities. If physical disturbance is severe, community development will be limited to a few species in a simple food web (Connell 1978, Menge and Sutherland 1987, Menge 2000).
Biotic interactions become more important as disturbance frequency decreases (Connell 1978, Menge and Sutherland 1987). If physical disturbance is rare, time is available for competitive exclusion to eliminate pioneer species in favor of the few who are best able to exploit available resources (Hardin 1960). Time (between disturbances) also allows for establishment of specialists, within the limits of carrying capacity (Odum 1969, Odum 1988, Ricklefs and Miller 2000). If the resource is large or the form of the resource is diverse, or both, then specialization may enhance species diversity (Williams 1943, He and Legendre 2002). Intermediate levels of disturbance often promote the greatest diversity (Connell 1978). The recruitment aspect of the theory (including immigration and emigration) modifies the effects of disturbance on diversity and addresses some island biogeography issues and local extinction-recolonization effects (Andrewartha and Birch 1954, MacArthur and Wilson 1967, Menge and Sutherland 1987, Menge 2000). Menge and Sutherland (1987) describe some classic examples of varying diversity with intensity and frequency of physical removal of dominant algae or mussels from several marine intertidal communities. Spatial influences are also important and operate at a wide range of scales. Island Biogeography has been the primary theory explaining the critical influences of habitat size, connectedness, and spatial arrangement on natural communities (MacArthur and Wilson 1967). It is easier for organisms to find and colonize large habitats and those near their population sources than those that are small or distant, or both. These processes appear to apply across a wide range of spatial scales. Hanski and Gilpin (1997) provided tools and terminology to develop Levin's (1969) concept of metatpopulations. This has become a central concept in Conservation Biology, because it allows us to understand the dynamics of spatiallystructured populations and deal with the effects of habitat fragmentation. Recently Hubbell (2001) expanded this concept (and MacArthur and Wilson's Island Biogeography) and developed a unified theory of biogeography that makes the link between species richness and relative species abundances within various interconnected habitat patches, based on birth, death, and migration processes. He shows how community structure and dynamics is largely dependent on the size of source populations relative to local populations within a metapopulation and the abilities of the organisms to move among appropriate habitat patches. Leibold et al. 
(2004) compared and contrasted four general metacommunity types, including Neutral Model, Patch Dynamics, Mass Effect, and Species Sorting, providing some distinguishing characteristics. Falke and Fausch (2010) conducted a meta-analysis of studies on stream fish metacommunities and evaluated the metacommunity of Great Plains (USA) stream fish assemblages, and found evidence for both the Mass Effect and Species Sorting paradigms.

The above compilation of theories is of course, a simplification and debate on each point continues (e.g., Connell 1980, Pimm and Kitching 1987, Strong 1992, He and Legendre 2002). However, it serves as a useful framework within which to examine the hypothesized mechanisms that alter or maintain complex wetland communities.

\section{LITERATURE CITATIONS UNIQUE TO APPENDIX 2; OTHER REFERENCE NUMBERS MATCH CITATIONS IN THE MAIN DOCUMENT}

Andrewartha, HG \& Birch, LC (1954) The distribution of abundance of animals, University of Chicago Press, Chicago.

Connell, JH (1980) Diversity and coevolution of competitors, or the ghost of competition past. Oikos, 35, 131-8.

Connell, JH (1985) The consequences of variation in initial settlement vs. post-settlement mortality in rocky intertidal communities. Journal of Experimental Marine Biology and Ecology, 93, 11-45.

Elton, C (1927). Animal ecology. Macmillan, New York.

Hairston, NG, Smith, FE \& Slobodkin, LB (1960) Community structure, population control, and competition. American Naturalist 94, 4215.

Hardin, G (1960) The competitive exclusion principle. Science, 131, 12921297.

Levin, R (1969) Some demographic and genetic consequences of environmental heterogeneity for biological control. Bulletin of the Entomological Society of America, 15, 237-40.

Lindeman, R (1942) The trophic-dynamic aspect of ecology. Ecology, 23, 399-418.

Lotka, AJ (1925) Elements of physical biology. Williams and Wilkins, Baltimore, Maryland.

Odum, EP (1969) The strategy of ecosystem development. Science, 164, $262-70$.

Odum, HT (1988) Self-organization, transformity, and information. Science, 242, 1132-9.

Oksanen, L, Fretwell, SD, Arruda, J \& Niemelä, P (1981) Exploitation ecosystems in gradients of primary productivity. American Naturalist, 118, 240-261.

Pearl, R \& Reed, LJ (1920) On the rate of growth of the population of the United States since 1790 and its mathematical representation. Proceeding of the National Academy of Science, USA, 6, 275-88.

Pimm, SL \& Kitching, RL (1987) The determinants of food chain lengths. Oikos, 50, 302-7.

Roughgarden, J, Iwasa, Y \& Baxter C (1985). Demographic theory for an open marine population with space-limited recruitment. Ecology, 66, 54-67.

Scheiner, SM \& Willig, MR (2005) Developing unified theories in Ecology as exemplified with diversity gradients. American Naturalist, 166, 458-69.

Strong, DR (1992) Are trophic cascades all wet? Differentiation and donorcontrol in speciose ecosystems. Ecology, 73, 747-54.

Svärdson, G (1976) Interspecific population dominance in fish communities of Scandinavian lakes. Report of the Institute of Freshwater Research Drottningholm, 55, 144-71.

Williams, CB (1943) Area and number of species. Nature, 152, 264-7.

\section{REFERENCES}

Baldassarre, GA \& Bolen, EG (2006) Waterfowl ecology and management, $2^{\text {nd }}$ ed, Krieger Publishing Company, Malabar, Florida.

Beisner, BE, Peres-Neto, PR, Lindstrom, ES, Barnett, A \& Longhi, ML (2006) The role of environmental and spatial processes in structuring lake communities from bacteria to fish. Ecology, 87, 2985-91.

Boesch, DF (1977) Application of numerical classification in ecological investigations of water pollution. Virginia Institute of Marine Science, Special Scientific Report No. 77, p. 113

Bogan, MT \& Boersma, KS (2012) Aerial dispersal of aquatic invertebrates along and away from arid-land streams. Freshwater Biology, 31, $1131-44$.

Brinson, MM, Lugo, AE\&Brown, S (1981) Primary productivity, decomposition and consumer activity in freshwater wetlands. Annual Review of Ecology and Systematics, 12, 123-61.

Brooks RT (2000) Annual and seasonal variation and the effects of hydroperiod on benthic macroinvertebrates of seasonal forest ("vernal") ponds in central Massachusetts, USA. Wetlands, 20, $707-15$.

Connell, JH (1978) Diversity in tropical rain forests and coral reefs. Science, 199, 1302-10.

Committee on Restoration of Aquatic Ecosystems: Science, Technology, and Public Policy (1992) Restoration of Aquatic Ecosystems, National Academy Press, Washington D.C.

Dahl, TE (1990) Wetland losses in the United States: 1780's to 1980's. U.S Department of the Interior, Fish and Wildlife Service, Washington, D.C.

Eadie, J \& Keast, A (1984) Resource heterogeneity and fish species diversity in lakes. Canadian Journal of Zoology, 62, 1689-95.

Falke, JA \& Fausch, KD (2010) From metapopulations to metacommunities: linking theory with empirical observations of the spatial population dynamics of stream fishes. American Fisheries Society, Symposium 73. Bethesda, MD; 207-33.

Fattorini, S (2005) A simple method to fit geometric series and broken stick models in community ecology and island biogeography. Acta Oecologica, 28, 199-205.

Fisher, RA, Corbet, AS\&Williams, CB (1943) The relation between the number of species and the number of individuals in a random sample of an animal population. Journal of Animal Ecology, 12, $42-58$.

Fretwell, SD (1987) Food chain dynamics: the central theory of ecology? Oikos, 50, 291-301.

Gosselink, JG \& Turner, GE (1978) In: Good, RE, Whigham, DF \& Simpson, RL (Eds.) Freshwater Wetlands: Ecological Processes and Management Potential, New York, Academic Press 63-78.

Hall, DL, Willig, MR, Moorhead, DL, Sites, RW, Fish, EB \& Mollhagen, TR (2004) Aquatic macroinvertebrate diversity of playa wetlands: the role of landscape and island biogeographic characteristics. Wetlands, 24, 77-91.

Hanski, IA \& Gilpin, ME (1997). Metapopulation biology: ecology, genetics and evolution. Academic Press, San Diego, CA.

Harris, HJ, Milligan, MS\&Fewless, GA (1983) Diversity: Quantification and ecological evaluation in freshwater marshes. Biological Conservation, 27, 99-110.

He, F, Legendre, P (2002) Species diversity patterns derived from speciesarea models. Ecology, 83, 1185-98.

Hilsenhoff, WL (1987) An improved biotic index of organic stream pollution. Great Lakes Entomology, 20, 31-9.

Holyoak, M \& Leibold, MA, Hold, RD (2005) Metacomunities: spatial dynamics and ecological communities. University of Chicago Press, Chicago.

Howeth, JG \& Leibold, MA (2008) Planktonic dispersal dampens temporal trophic cascades in pond metacommunities. Ecology Letters, 11, 245-57.

Howeth, JG \& Leibold, MA (2010a) Prey dispersal rate affects prey species composition and trait diversity in response to multiple predators in metacommunities. Journal of Animal Ecology 79, 1000-11.

Howeth, JG\&Leibold, MA (2010b) Species dispersal rates alter diversity and ecosystem stability in pond metacommunities. Ecology, 91, $2727-41$.

Hubbell, SP (2001) The unified neutral theory of biodiversity and biogeography. Princeton University Press, Princeton.

Hynes, HBN (1972) The ecology of running waters. University of Toronto Press, Toronto.

Jenkins, B, Kitching, RL \& Pimm, SL (1992) Productivity, disturbance and food web structure at a local spatial scale in experimental container habitats. Oikos, 65, 249-55.

Jongman, RHG, ter Braak, CJF \& van Tongeren, OFR (1995) In: Data analysis in community and landscape ecology. New York, Cambridge University Press, 91-173. 
Jude, DJ\&Pappas, J (1992) Fish utilization of Great Lakes coastal wetlands. Journal of Great Lakes Research, 18, 651-72.

Karr, JR (1981) Assessment of biotic integrity using fish communities. Fisheries, 6, 21-7.

Kitchell, JF \& Carpenter, SR (1993) Cascading trophic interactions. The trophic cascade in lakes, Cambridge University Press, Cambridge.

Kobayashi, S\&Kimura, K (1994)The number of species occurring in a sample of a biotic community and its connections with speciesabundance relationship and spatial distribution. Ecological Research, 9, 281-94.

Krieger, KA (1992) The ecology of invertebrates in Great Lakes coastal wetlands: current knowledge and research needs. Journal of Great Lakes Research, 18, 634-50.

Leibold, MA, Holyoak, M, Mouquet, M, Amaraskare, P\&Chase, JM, (2004) the metacommunity community concept: a framework for multiscale community ecology. Ecology Letters, 7, 601-13.

Lubchenco, J\&Gaines, SD (1981) A unified approach to marine plantherbivore interactions, I. Populations and communities. Annual Review of Ecology and Systematics 12, 405-37.

Lugo, AE (1990) Fringe wetlands Forested wetlands, ecosystems of the world 15. Elsevier, Amsterdam 143-69.

MacArthur, RH \& Wilson, EO (1967) The Theory of Island Biogeography, Princeton University Press, Princeton.

Mandrak, NE \& Crossman, EJ (1992) Postglacial dispersal of freshwater fishes into Ontario. Canadian Journal of Zoology, 70, 2247-59.

Matthews, WJ (1998) Patterns in freshwater fish ecology. Chapman and Hall, New York.

McKenna, JEJr (2003b) An Enhanced Cluster Analysis Program with Bootstrap Significance Testing for Ecological Community Analysis. Environmental Modeling \& Software, 18, 205-20.

McKenna, JEJr (2003a) Community metabolism during early development of a restored wetland. Wetlands, 23, 35-50.

Menge, BA (1983) Components of predation intensity in the low zone of the New England rocky intertidal community. Oecologia, 58, 141-55.

Menge, BA (2000) Top-down and bottom-up regulation in marine rocky intertidal habitats. Journal of Experimental Marine Biology and Ecology, 250, 257-89.

Menge, BA \& Sutherland, JP (1976) Species diversity gradient: synthesis of the roles of predation, competition, and temporal heterogeneity. American Naturalist, 110, 351-69.

Menge, BA \& Sutherland, JP (1987) Community regulation: variation in disturbance, competition, and predation in relation to environmental stress and recruitment. American Naturalist,130, 730-57.

Merritt, RW\&Cummins, KW (1984) An introduction to the aquatic insects of North America, $2^{\text {nd }}$ ed, Kendall/Hunt Publication Company, Iowa.

Mitsch, WJ \& Gosselink, GJ (2006) Wetlands, $4^{\text {th }}$ ed., John Wiley and Sons, Inc., New York.

Montezuma National Wildlife Refuge (2008) Montezuma National Wildlife Refuge, Draft Habitat Management Plan, Available from http://friendsofmontezuma.org/ftp/pub/HMP_0708.pdf.

Muller, EH, Prest, VR (1985) In: Karrow, PF \& Calkin, PE (Eds.) Quaternary Evolution of the Great Lakes: Geological Society of Canada Special Paper, 30. 213-239.

Nemec, A \& Brinkhurst, RO (1988) Using the bootstrap to assess statistical significance in the cluster analysis of species abundance data. Canadian Journal of Fisheries and Aquatic Sciences, 45, 965-70.

Peckarsky, BL, Fraissinet, PR, Penton, MA\&Conklin, DAJr (1990) Freshwater macroinvertebrates of northeastern North America. Cornell University Press, Ithaca.

Pennak, RW (1989) Freshwater invertebrates of the United States, $3^{\text {rd }}$ ed, John Wiley and Sons, New York.

Polis, GA\&Winemiller, KO (1996) Food webs International, Thomas Publishing, New York.

Power, ME, Parker, MS\&Wootton, JT (1996) In: Polis, GA\&Winemiller, KO (Eds.) Food webs, integration of patterns and dynamics, New York, Chapman and Hall, New York 286-7.
Presley, SJ, Cisneros, LM, Patterson, BD \& Willig, MR (2012) Vertebrate metacommunity structure along an extensive elevational gradient in the tropic: a comparison of bats, rodents and birds. Global Ecology and Biogeography, 21, 968-76.

Preston, FW (1948) The commonness, and rarity, of species. Ecology, 29, 254-83.

Proctor, VW \& Malone, CR (1965) Further evidence of the passive dispersal of small aquatic organisms via the intestinal tract of birds. Ecology, 46, 728-9.

Ricklefs, RE \& Miller, GL (2000) Ecology, $4^{\text {th }}$ ed. W.H. Freeman and Company, New York.

Robinson, CLK \& Tonn, WM (1989) Influence of environmental factors and piscivory in structuring fish assemblages of small Alberta lakes. Canadian Journal of Fisheries and Aquatic Sciences, 46, 819.

Ruhí,A, Boix, D, Gascón, S, Sals, J \& Quintana, XD(2013) Nestedness and successional trajectories of macroinvertebrate assemblages in manmade wetlands. Oecologia, 171(2), 545-56.

Saila, SB, McKenna, JE, Formacion, S, Silvestre, GT\&McManus, J (1996) In: Gallucci, VF, Saila, SB, Gustafson, DJ \& Rothschild, BJ (Eds.) Stock assessment, quantitative methods and applications for smallscale fisheries. New York, Lewis Publishers 403-72.

Schaffner, WR \& Oglesby, RT (1978). In: Bloomfield, JA (Ed.) Lakes of New York State. Volume 1, Ecology of the Finger Lakes. Limnology of eight Finger Lakes: Hemlock, Canadice, Honeoye, Keuka, Seneca, Owasco, Skaneateles, and Otisco, New York, Academic Press, 313-470.

Schlichting, HEJr (1960) The role of waterfowl in the dispersal of algae. Transactions of the American Microscopal Society, 79, 160-6.

Shannon, CE \& Weaver, W (1949) The mathematical theory of communication. University of Illinois Press, Illinois.

Shepard, RB (1984) The logseries distribution and Mountford's similarity index as a basis for the study of stream benthic community structure. Freshwater Biology, 14, 53-71.

Shmida, A \& Wilson, MV (1985) Biological determinants of speciesdiversity. Journal of Biogeography, 12, 1-20.

Smith, CL (1985) The inland fishes of New York State. New York Department of Environmental Conservation, New York.

Steedman, RJ \& Regier, HA (1987) Ecosystem science for the Great Lakes: perspectives on degradative and rehabilitative transformations. Canadian Journal of Fisheries and Aquatic Science, 44, 95-103.

ter Braak, CJF (1986) Canonical correspondence analysis: a new eigenvector technique for multivariate direct gradient analysis. Ecology, 67, 1167-79.

ter Braak, CJF (1988) CANOCO - a FORTRAN program for canonical community ordination. Microcomputer Power, New York.

Turner, RE (1988) Fish and fisheries of inland wetlands. Water Quality Bulletin, 13, 7-13.

U.S. Fish and Wildlife Service (1988) Progress report to Congress, National Wetlands Inventory, Department of the Interior, Washington, DC.

Voigts, DK (1976) Aquatic invertebrate abundance in relation to changing marsh vegetation. American Midland Naturalist, 95, 312-22.

Ward, P\&Zahavi, A (1973) The importance of certain assemblages of birds as "information-centres" for food finding. Ibis, 115, 517-34.

Weller, MW (1981) Freshwater marshes, University of Minnesota Press, Minnesota.

Welty, JC (1973). The life of Birds, $2^{\text {nd }}$ ed, W. B. Saunders Company, Philadelphia.

Wentworth, CK (1922) A scale of grade and class terms for clastic sediments. Journal of Geology 30, 377-92.

Whittaker, RH (1972) Evolution and measurement of species diversity. Taxon 21, 213-51.

Zar, JH (1989) Biostatistical analysis, $4^{\text {th }}$ ed, Prentice Hall, New Jersey.

Zimmer, KD, Hanson, MA \& Butler, MG (2000) Factors influencing invertebrate communities in prairie wetlands: a multivariate approach. Canadian Journal of Fisheries and Aquatic Science, 57, 76-85. 